\title{
Competition in Lending: Theory and Experiments*
}

\author{
Elena Asparouhova \\ University of Utah
}

This version: January 2006

\begin{abstract}
A variation of the Rothschild-Stiglitz' equilibrium is examined in the context of competitive lending under adverse selection. The predictions of the model are tested in an experimental market setting. If equilibrium exists, it predicts that the loan contracts offered and taken separate the projects being financed by quality. When equilibrium exists, the experiments confirm the theory. The entrepreneurs with high-risk projects take bigger loans and bear higher credit spreads than those with low-risk projects. When equilibrium does not exist, which happens exactly when the candidate for equilibrium does not provide a Pareto-optimal allocation, in half of the sessions loan trading stabilizes around the candidate equilibrium pair. In the other half, however, markets never settle down. This finding has important implications. When lenders can offer menus of contracts, as is usually the case in the real world, the outcome may not be the zero-profit separating contracts of the standard model in the theory of corporate finance. Worse, as an example in the paper illustrates, fitting the standard model to field data may lead to serious biases in estimated parameters while falsely accepting the model's main restriction (separation).
\end{abstract}

${ }^{*}$ The financial support of the Division of Humanities and Social Sciences at Caltech is gratefully acknowledged. I would like to thank Charles Plott, Thomas Palfrey, Bill Zame, Mike Lemmon, as well as the seminar participants at Caltech, UCSD, Duke, Berkeley, Stanford, University of Utah, Columbia, Georgia State University, Tulane, University of Houston, and Arizona State University for helpful comments. I am especially grateful to Peter Bossaerts for all his suggestions and comments, and the staff of EEPS, SSEL, and CASSEL for their help in running the experiments. All errors are my own. 


\section{Introduction}

Beginning with the seminal papers of Ross (1977) and Leland and Pyle (1977), corporate finance has asked about the choice of financial contracts (e.g., debt, equity) in environments with asymmetric information. In particular, this literature asks whether the financial contracts offered will separate firms into different risk categories. This paper uses an experimental environment to study the financial contracts offered and chosen, and the separation of firms, when lenders compete.

The experiments are built on a variation of the familiar Rothschild and Stiglitz (1976) (henceforth RS) model of markets with adverse selection. Risk-averse entrepreneurs need outside financing for projects of differential quality, known only to them. Risk-neutral lenders provide financing contracts called loans 1 Loans are distinguished by the amount of the required investment they cover, i.e., by their leverage, and by the credit spread charged to borrowers. Lenders know the population distribution of all projects but they cannot observe the quality of individual projects.

In this setup, RS propose a plausible notion of competitive equilibrium. In this equilibrium each contract offered by a lender must break even in expectation when entrepreneurs optimally choose contracts, and there should exist no other contract which, if offered, would make a nonnegative expected profit $L^{2}$ The feature of this equilibrium notion that has attracted most attention in the literature is that there are robust regions of non-existence. Moreover, when it does exist, the competitive equilibrium does not necessarily lead to a (constrained) Pareto-optimal allocation.

$\mathrm{RS}$ restrict the lenders to offer single contracts. Here, this assumption is relaxed by allowing each lender to simultaneously offer multiple loan contracts. Consequently, the RS notion of competitive equilibrium is generalized to the notion of equilibrium in menus of contracts. In parallel with the RS definition, each contract in the set of equilibrium contracts offered by a lender must break even in expectation when entrepreneurs optimally choose their contracts, and there should exist no other set of contracts which, if offered, would make a nonnegative expected profit. An equilibrium in menus of

\footnotetext{
1 The borrowing-lending setting is used for the sake of clarity. Of course, the RS model applies to a broader class of markets that are subject to adverse selection. The questions posed in this paper concern any such markets. Since our experiments are conducted context-free, the results of this paper apply to the broader settings. The actors in the RS model are labeled "insurance companies" and "potential policyholders" rather than "lenders" and "entrepreneurs" but the difference is only one of interpretation.

${ }^{2}$ Each lender is assumed to hold the Nash conjecture, i.e., each lender assumes that the set of contracts offered by the other lenders is independent of his own actions.
} 
contracts exists exactly when the RS equilibrium in single contracts exists (which it may not) and is Pareto-optimal, in which case the two coincide. Thus, equilibrium in menus of contracts fails to exist exactly when there is a tension between competition and Pareto-optimality. On the one hand competition requires that the expected profits for each of the candidates for equilibrium contracts (conditional on the type of project being financed) be zero. On the other hand, a menu of contracts that is Pareto-dominating will be offered even if its contracts do not satisfy the zero-profit condition (such a menu is called "crosssubsidized" menu of contract: $3^{3}$. Obviously, such a menu itself cannot be part of an equilibrium.

Two parameterizations of the generalized RS model are implemented in the experimental markets. In the first environment, called the Baseline environment, the RS equilibrium in single contracts exists, is constrained Pareto-optimal, and coincides with the equilibrium in menus of contracts. In the second environment, called the Non-Existence environment, the parameters are changed in a way so that competition would drive out the optimal contracts, theoretically that is, and the results are calibrated against the outcomes from the Baseline experiments. In the Non-existence environment the RS equilibrium in single contracts exists but is not Pareto-optimal; the equilibrium in menus of contracts does not exist.

The experiments for this study are organized around an open-book one-sided continuous auction mechanism. Each lender can (anonymously) offer any set of contracts while each entrepreneur can accept a single contract among those offered by the lenders. Using this particular market structure we study to what extent it generates the theoretical predictions of the generalized RS equilibrium notion.

The purpose is twofold. On the one hand the aim is to discover whether actual markets attain equilibrium in the theoretically non-controversial case where a Pareto-optimal equilibrium exists. On the other hand we investigate the outcome resulting from competition when the Pareto-optimal outcome cannot be supported in equilibrium. One appealing alternative principle is that suboptimal contracts are ultimately eliminated from the markets. The purpose of the second part of the study is to discover whether such a principle might actually provide a better description of the market outcomes than competitive equilibrium does.

The results from the Baseline setting provide strong support for the theoretical predictions. In particular, the contracts offered separate the two types of projects: the high-risk projects are financed with bigger loans and higher interest payments than the low-risk projects. The experimental findings for the Non-existence setup are mixed. In three out of six sessions the RS equilibrium in single contracts outcome

\footnotetext{
${ }^{3}$ A "cross-subsidized" menu of contracts is such that the contract designed for the low-risk entrepreneurs makes a positive expected profit and the one designed for the high-risk entrepreneurs makes at most an offsetting expected loss.
} 
is reached. In the other three, cross-subsidized pairs of contracts are temporarily traded but markets never settle down. In the empirical analysis of the three "unstable" sessions the hypothesis that two types of contracts, one with high loan amount and high credit spread, and the other with low loan amount and credit spread, are transacted in the marketplace cannot be rejected. This result is in accordance with the theoretical prediction of separation. That markets are not in equilibrium is established only when the relative proportions of the two types of transacted contracts are examined. The theory predicts that the proportion of the high-loan high-credit-spread contracts among all transacted contracts should be equal to the proportion of high-risk projects in the pool of projects. The corresponding hypothesis is strongly rejected by the data. Consequently, the hypothesis that markets have attained equilibrium is also strongly rejected.

The experimental results are particularly informative about empirical analysis of field data. In the field (but unlike in the experiments), one cannot dissociate estimating the parameters and ascertaining whether equilibrium occurs. If the econometrician does not know the proportion of high-risk projects and lets structural econometrics tell him what it is, he will get the wrong results. Not only will he obtain wrong proportion estimates, the econometrician will also falsely conclude that the economy is in a separating equilibrium whereas in fact it is not in equilibrium at all.

In summary, when the equilibrium in menus of contracts exists, i.e., when the RS equilibrium in single contracts is Pareto-optimal, it predicts the observed outcomes in experiments. In the Non-existence setting, the evidence we obtain in favor of the RS' or any other alternative outcome is unconvincing. The latter finding is important, because it implies that the separating contracts often studied in the corporate finance literature are questionable in a competitive framework where lenders offer the contracts (i.e., when the setup is one of screening and not of signaling). When lenders can offer menus of contracts, the zero-profit separating contracts derived in the corporate finance literature may not survive competition. Worse, the evidence suggests that in some cases no stable set of contracts will arise when the zero-profit separating contracts are not Pareto-optimal.

\section{Related Literature}

There is abundant theoretical literature on the puzzle of nonexistence of the RS' competitive equilibrium. Advancing other notions of equilibrium in addition to altering the strategy space, or changing the sequential structure of the economy, those models resolve the non-existence issue. Within the single- 
contract restriction, Wilson (1977) assumes that firms (lenders) anticipate the reaction of other firms before offering a deviating contract 4 In this model a pooling contract emerges when the RS equilibrium in single contracts does not exist. Miyazaki (1977) and Spence (1978) allow firms to offer menus of contracts while still using the Wilson conjecture in equilibrium. The outcome of the Wilson equilibrium in menus of contracts is always a Pareto-optimal pair. Riley (1979a) replaces the Nash conjecture with one where firms anticipate further entries when they consider offering deviating contracts. As a result the RS candidate for equilibrium outcome is sustained even when the RS equilibrium does not exist. Dasgupta and Maskin (1986) prove existence of Nash equilibrium in mixed strategies for the game corresponding to the RS setup but excluding free entry. The equilibrium strategy has a support of a continuum of crosssubsidized pairs in the cases when the RS equilibrium in menus of contracts does not exist. Dubey and Geanakoplos (2002) restore existence in a general equilibrium framework. However, absent the particular refinement structure used in their model, there is an enormous multiplicity of equilibria. Ania et al. (2002) provide evolutionary analysis of the markets with adverse selection and conditions under which they attain equilibrium. While each model in this short in comparison to the existing literature list provides an appealing alternative to the principles behind the RS notion of equilibrium, assessing which of the principles governs actual markets is ultimately an empirical question.

There are a few related experimental papers. The closest is Posey and Yavas (2003). It studies experimental insurance markets where sellers can compete on the prices of (only) two insurance contracts. The sellers move first and offer contracts; the buyers move second and choose (in fact, the buyers' decisions are made by computers). Posey and Yavas find strong support that the two contracts are priced to generate zero expected profits, thus supporting one element of the RS theory. In our experiments, the contract space is substantially enriched. In addition, we do not computerize the buyers' side. We use a different market microstructure, namely the open book, which has been shown to induce more competition. Miller and Plott (1985) study adverse selection in experimental double-auction markets. Because of its great complexity (allowing for both signalling and screening), the underlying theoretical model does not give a unique prediction for the market equilibrium, which perhaps explains why the results are mixed, with both pooling and separation emerging. Whenever separation obtains, the level of the signal is not at its optimal level. In our opinion, screening is more natural in the context of lending

\footnotetext{
${ }^{4}$ In the Wilson equilibrium each contract offered by a lender must break even in expectation when entrepreneurs optimally choose contracts, and there should exist no other contract which, if offered, would make a nonnegative expected profit after the elimination of all the existing contracts thereby rendered unprofitable.
} 
as the lenders offer the terms of the contracts, not the borrowers. Our experimental markets are closer to the theory, and therefore, simpler. Goswami et al. (2002) investigate demand and provision of corporate insurance in an experimental setting. Firms first signal their type by announcing what level of insurance coverage they would like to purchase and then insurers compete on the price of it. Similarly, Cadsby at al. (1990) also study separation in the context of a signaling model. Again, we investigate the issue of separating within a screening model.

The remainder of the paper is organized as follows. The next section provides a brief description of the model and the theoretical results. Section 4 goes over the experimental design and describes the laboratory markets. Summary of the experimental sessions is given in Section 5 . The conjectures to be tested later on are in Section 6, while the results are presented in Section 7 . Section 8 concludes the paper.

\section{Description of the Model}

This section first revisits the RS model of adverse selection in a lending context. Next, the single contract constraint in the RS model is relaxed by allowing lenders to offer multiple contracts and the equilibrium in menus of contracts is introduced. The section then links Pareto-optimal provision of contracts with existence of equilibrium in menus of contracts. It should be noted that Rothschild and Stiglitz (1976) discusses the possibility of allowing firms to offer multiple contracts but without providing a formal equilibrium definition. A solution to the problem of optimal provision of contracts is also provided in that article. As most of it is adapted from Rothschild and Stiglitz (1976), the current section is rather brief and the interested reader is referred to the original article for more details.

The economy in this model is populated by entrepreneurs and lenders. Each entrepreneur has access to a project that requires initial outlay of $I$. The outcome of the project can be either good or bad with corresponding payoffs of $X_{g}$ and $X_{b}, X_{g}>X_{b} \geq 0$.

Entrepreneurs are of two types. Those of the high-risk type lead their project to a bad outcome with probability $p_{h}$, while this probability is equal to $p_{l}$ for the low-risk type, where $p_{h}>p_{l}{ }^{5}$ All entrepreneurs are risk averse with preferences represented by the utility function $U(x)\left(U^{\prime}(x)>0, U^{\prime \prime}(x)<0\right)$, and all have initial endowment of $W$.

\footnotetext{
${ }^{5}$ Alternatively one can think of the projects being of differential quality with the high-risk (low-risk) projects having probability of a bad outcome equal to $p_{h}\left(p_{l}\right)$. Entrepreneurs' types are determined from the quality of their projects.
} 
Profit-maximizing lenders offer loan contracts to the entrepreneurs defined by the amount loaned $L$, and the face value of the loan $F$. More specifically, a contract $(L, F)$ between a lender and an entrepreneur entitles the entrepreneur to receive $L$ from the lender before a project is undertaken, and obliges him to pay back $\operatorname{Min}(X, F)$ after the realization of the project, where $X$ is the project's payoff. $S \subset \mathbb{R}^{2}$ is the set of loan contracts available for the lenders to offer.

Lenders do not know the individual entrepreneurs' types but they know the proportion of the highrisk entrepreneurs, $\lambda$. Thus, when offering loan contracts, lenders face adverse selection as they cannot distinguish between high and low-risk entrepreneurs. The market for loans is competitive in the sense that there is free entry.

In this setup we first consider the notion of equilibrium introduced by Rothschild and Stiglitz (1976). We refer to it as equilibrium in single contracts.

Definition 3.1 Equilibrium in single contracts is a set of contracts such that when entrepreneurs choose contracts to maximize expected utility, (i) no contract in the equilibrium set makes negative expected profits; and (ii) there is no contract outside the equilibrium set that, if offered, will make a nonnegative profit.

This notion generates robust regions of equilibrium non-existence as well as equilibrium sub-optimality when the set of all possible loan contracts is $S=\mathbb{R}^{2}$. When equilibrium exists it is always a separating one, i.e., it entails a pair of contracts offered by the lenders, with high-risk entrepreneurs taking one of them, and the low-risk entrepreneurs taking the other. Competition requires that the equilibrium loan contracts break even in expectation conditional on the type of entrepreneurs undertaking them ${ }^{6}$ Because the latter is not a requirement for Pareto-optimal provision of contracts, the equilibrium set of contracts

\footnotetext{
${ }^{6}$ From all zero-profit contracts intended for the high-risk agents, in equilibrium, the lenders must offer the one that maximizes the high-risk entrepreneurs' utility. The lenders cannot offer the zero-profit utility-maximizing contract to the low-risk agents as the high-risk agents would also undertake it, making lenders lose money on it. From all zeroprofit contracts intended for the low-risk agents, in equilibrium, the lenders must offer the one that makes the high-risk entrepreneurs indifferent between undertaking the loan contract designed for them and undertaking the one designed for the low-risk entrepreneurs.
} 
is not necessarily Pareto-optimal[7 Moreover, equilibrium in the RS model does not exist exactly when a single (pooling) contract Pareto-improves upon the candidate for equilibrium separating pair of contracts.

RS restricts lenders to offer single contracts. A natural notion of equilibrium when this restriction is relaxed and lenders are allowed to offer multiple contracts is the following variation of the RS equilibrium, which we call equilibrium in menus of contracts:

Definition 3.2 Equilibrium in menus of contracts is a set of contracts such that when entrepreneurs choose contracts to maximize expected utility, (i) no contract in the equilibrium set makes negative expected profits; and (ii') there is no menu of contracts outside the equilibrium set that, if offered, will make a total nonnegative expected profit.

In addition to being unrealistic, the RS' restriction on lenders to offer single contracts obscures the intuition behind equilibrium non-existence. With the restriction relaxed, the equilibrium in menus of contract does not exist exactly when the zero-profit contracts identified by RS as the only possible candidate for equilibrium do not provide a Pareto-optimal allocation. Thus, with menus of contracts, the tension between competition and optimality is what causes equilibrium to fail to exist. On the one hand competition requires that the expected profits for each of the candidates for equilibrium contracts be zero. On the other hand, if no pair of zero-profit contracts provides an optimal allocation, competition implies that a cross-subsidized pair of Pareto-dominating contracts will be offered. In each such pair, the contract designed for the high-risk agents loses money (in expectation) while the one for the low-risk agents makes positive expected profit with an overall non-negative expected profit from the two contracts 8 Because it violates the zero-profit requirement on the individual contracts, such a menu itself cannot be part of an equilibrium. This tension between equilibrium and Pareto-improving contracts is what keeps markets from equilibrating.

The parametrization of the model used in the experimental design is presented next.

\footnotetext{
${ }^{7} \mathrm{An}$ allocation of contracts between the lenders and the entrepreneurs is (constrained) Pareto-optimal if a benevolent central planner who possesses the same information as the lenders cannot allocate contracts between the lenders and the entrepreneurs in a way that would make everybody weakly better off and at least one agent (a lender or an entrepreneur) strictly better off.

${ }^{8}$ In the real world, cross-subsidized pairs may survive only because of entry restrictions. For instance, exclusive group health insurance provision to employees of a firm often entails a cross-subsidization of the more healthy to the less healthy employees without third parties being able to undercut (because they do not have access to the employees).
} 


\subsection{Parametrization Used for the Experimental Design}

The entrepreneurs' utility function is set to $U(x)=x-\frac{1}{2} b x^{2}$, where $b=0.0089^{9}$ Initial wealth is $W=0$, while the payoff of the project in the good (bad) state is $X_{g}=100\left(X_{b}=0\right)$.

The high-risk entrepreneurs' probability of leading the project to a bad outcome is $p_{h}=7 / 9$, while this probability is $p_{l}=5 / 9$ for the low-risk agents. For simplicity, the cost of the investment, $I$, is set to zero (i.e., the lending contracts serve a consumption-smoothing function only). Each lender is endowed with the utility function $U_{L}(x)=10 x$.

For the purposes of our experimental design, a contract is defined by the pair $(\alpha, \beta)=(F, F-L)$, and $F-L$ is referred to as "credit spread."

The expected utility of an entrepreneur of type $i, i=h, l$ upon obtaining the contract $(\alpha, \beta)$ is

$$
U_{i}(\alpha, \beta)=E_{i}(U(x) \mid(\alpha, \beta))=\left(1-p_{i}\right) U(100-\beta)+p_{i} U(\alpha-\beta) .
$$

Similarly, a lender gets

$$
U_{L}(\alpha, \beta, i)=E\left(U_{L}(x) \mid(\alpha, \beta), i\right)=\left(1-p_{i}\right) U_{L}(\alpha)-U_{L}(\alpha-\beta)
$$

in expectation from the contract $(\alpha, \beta)$ with a type $i, i=h, l$ agent.

The RS candidate for equilibrium (in single contracts) pair consists of the contract $\left(\alpha^{h *}, \beta^{h *}\right)=$ $(100,78)$, designed for the high-risk entrepreneurs, and $\left(\alpha^{l *}, \beta^{l *}\right)=(23,13)$ for the low-risk ones 10

For the values of the parameter $\lambda$ used in the experimental design, and when $S=\mathbb{R}^{2}$, the equilibrium in single contracts under the above parametrization exists but is not (constrained) Pareto-optimal ${ }^{11}$ The equilibrium in menus of contracts does not exist.

Two treatments, called Baseline and Non-existence, are created using the above parametrization. In the Baseline environment the contract space is discretized in such a way, so that the RS' equilibriumin-single-contracts pair is included while all pairs that Pareto-dominate it are not. The resulting set

\footnotetext{
${ }^{9}$ Affine transformations of $U(x)$ are used in the tabulation of the payoffs in actual experiments. $U_{h(l)}(x)$ denotes the function for the high-risk (low-risk) entrepreneurs. $U_{l}(x)=20 U(x)-522$, while $U_{h}(x)=10 U(x)-121$.

${ }^{10}$ The derivation of those contracts is not included for the sake of brevity. The contract $\left(\alpha^{h *}, \beta^{h *}\right)$ for the high-risk entrepreneurs is derived by a simple constrained maximization of $U_{h}(\alpha, \beta)$ subject to the zero-profit condition $U_{L}(\alpha, \beta, h)=$ 0 . The contract $\left(\alpha^{l *}, \beta^{l *}\right)$ for the low-risk entrepreneurs is then the only contract that satisfies both the zero-profit condition $U_{L}(\alpha, \beta, l)=0$ and the incentive compatibility condition $U_{h}(\alpha, \beta)=U_{h}\left(\alpha^{h *}, \beta^{h *}\right)$.

${ }^{11}$ For example if $\lambda=6 / 11$ the zero-profit optimal pair of contracts is $\left(\alpha^{l}, \beta^{l}\right)=(40.05,25.39)$ (the contract intended for low-risk entrepreneurs), and $\left(\alpha^{h}, \beta^{h}\right)=(100,75)$ (the contract for high-risk entrepreneurs). This is a cross-subsidized pair of contracts: $\left(\alpha^{h}, \beta^{h}\right)$ brings a strictly positive profit to the lenders, with exactly offsetting loss from $\left(\alpha^{l}, \beta^{l}\right)$.
} 
of contracts is denoted $S^{\prime}$. Thus, in the Baseline environment, the equilibrium in menus of contracts exists and is Pareto-optimal with respect to $S^{\prime}$. The discretization of the contract space creates a second possible RS equilibrium contract for the high-risk entrepreneurs, namely $\left(\alpha^{h *}, \beta^{h *}\right)^{\prime}=(95,74)$.

In the Non-existence environment, the contract space $S^{\prime}$ is altered in a way to include pairs of contracts that Pareto-dominate the equilibrium-in-single-contracts pair. The newly chosen set of contracts is denoted $S^{\prime \prime}$. The existence of Pareto-improving contracts is what precludes markets from attaining the equilibrium in menus of contracts. Thus, in the second environment, the equilibrium in single contracts exists but there are pairs of contracts that Pareto-dominate it, and, as a result, the equilibrium in menus of contracts does not exist.

\section{Experimental Design}

\subsection{The Laboratory Markets}

Each experimental market session consisted of 10 to 14 identical trading periods, each with length from three to ten minutes ${ }^{12}$ Most Baseline session consisted of 10 trading periods ${ }^{13}$ The number of trading periods was increased to 14 in the Non-existence sessions ${ }^{14}$

The contracts, defined as $(\alpha, \beta)$, were called "financial instruments," or "securities." In the Baseline environment, the possible contracts were given by

$\alpha \in\{8,16,20,23,26,34,44,55,65,75,85,95,100,105,110\}=\left(\alpha_{i}\right)_{i=1}^{15}$,

$\beta \in\{4,7,10,13,14,17,23,29,35,41,53,56,59,62,71,74,77,78,79,81,84,87,93\}=\left(\beta_{i}\right)_{i=1}^{23}$.

The following values were used in the Non-existence environment

$\alpha \in\{16,20,23,26,34,35.6,40.05,44,55,65,75,85,95,100,105,110\}=\left(\alpha_{i}\right)_{i=1}^{16}$,

$\beta \in\{7,10,13,14,17,22.3,23,25.39,29,35,41,53,56,59,62,71,74,75.16,75.95,76.65,78,79,81,84,87\}=$ $\left(\beta_{i}\right)_{i=1}^{25}$.

\footnotetext{
${ }^{12}$ Sessions started with longer periods and as the session progressed the length of the periods was shortened. This procedure is often employed in complex experiments because traders require time to learn about the trading technology, etc., but after such skills have been acquired the periods can be shortened (Hirota et al. (2005)). Also, the length of the periods was longer in the oral auction markets compared to the electronic ones.

${ }^{13}$ The standard number of repetitions for market experiments is usually 6-9 (See Bossaerts (2003)).

${ }^{14}$ The number of periods was increased because the Non-existence environment is the more difficult one for the subjects to learn experimentally. Still, whether 14 periods were enough and whether markets would have stabilized had there been several extra periods is an empirical question that further studies could address.
} 
In the Baseline environment, there were fifteen "markets," $\alpha_{1}, \ldots, \alpha_{15}$, called markets " $A$," " $B$, , " $C$," $\ldots$, and " $O$ " in the actual experiments. The contracts within each of the fifteen markets were determined by the "prices," $\beta_{1}, \ldots, \beta_{23}$, called simply "price 1 ," "price $2, " \ldots$, "price 23 " in the experiments. The contacts in the Non-existence environment were defined in a similar way. The markets were called " $A$," " $B, " \ldots$, and " $P$, , and the prices went from 1 to 2515

Figure 1 presents the grid of contracts used in the Baseline experiments, while Figure 2 is for the grid of the Non-existence environment.

The entrepreneurs in the experiments were called "buyers," while the lenders were "sellers." Each buyer could be of one of the two possible types - Red or Blue, corresponding to the high-risk and the low-risk entrepreneurs. Whether a participant in any given experimental session was a buyer or a seller was determined randomly in the beginning of the session. The type of a given buyer could change from period to period but the proportion of Red buyers, $\lambda$, was constant throughout the periods.

For the RS equilibrium in single contracts to exist, $\lambda$ has to be greater than 0.47 . The theory predicts that as long as $\lambda$ satisfies this restriction, the contracts $\left(\alpha^{h *}, \beta^{h *}\right)$, and $\left(\alpha^{l *}, \beta^{l *}\right)$ should emerge in equilibrium. Different values of lambda that satisfy the restriction were used in the Baseline treatment. This design feature is easily accommodated by the econometric analysis and provides a robustness check for the empirical results.

In the Non-existence treatment, on the other hand, whether on not a given pair of contracts Paretodominates the pair $\left(\alpha^{h *}, \beta^{h *}\right)$, and $\left(\alpha^{l *}, \beta^{l *}\right)$ depends on the value of $\lambda$. For that reason the value of $\lambda$ was fixed for all sessions.

Each lender was allowed to offer any number of contracts from those available. The entrepreneurs, on the other hand, could accept at most one contract per period. Moreover, the entrepreneurs could not send offers to the market, they could only accept existing lenders' offers ${ }^{16}$

\footnotetext{
${ }^{15}$ The contracts in the Baseline (Non-existence) treatment were presented to the subjects in a $15 \times 23(16 \times 25)(\alpha, \beta)$ table. The inclusion of loan amounts and credit spreads that are part of Pareto-dominating pairs in the Non-existence treatment necessarily increases the size of the contract space. Given the visual presentation, however, the difference in contract space sizes between treatments is small enough that the possibility of it causing difference in complexity can easily be excluded.

${ }^{16}$ The instructions for the Baseline environment can be found in the end of the paper.
} 


\subsection{Certainty Equivalent Payoffs}

Because of the difficulty of measuring and controlling risk attitudes of human subjects, we substituted leverage-dependent payoff schedules for uncertainty in the final payoffs of the projects. That is, rather than assuming that human subjects make decisions under uncertainty based on a specific expected-utility function with common parameters, we gave them payoffs that corresponded to the expected utility they would have gotten from each of the contracts had they really had the hypothesized risk attitudes. Thus, after obtaining a contract $(\alpha, \beta)$ a subject in the role of an entrepreneur of type $i, i=h, l$, did not face any uncertainty but instead earned $U_{i}(\alpha, \beta)$. Similarly, after providing a contract $(\alpha, \beta)$ to an entrepreneur of type $i, i=h, l$, a subject in the role of a lender received a payoff of $U_{L}(\alpha, \beta, i)$.

Each buyer was presented with a payoff table. Similarly, each seller was presented with a payoff table that indicated for each contract the possible payoff depending on what type of buyer accepts the contract (see Figure 3 for the payoff table presented to the sellers) 17

All payoffs were expressed in a fictitious currency called francs. Each participant's total franc earnings from an experimental session was equal to the cumulative earnings from all periods. In the end of the session the franc earnings were exchanged to dollars at a pre-announced rate.

\section{Summary of the Sessions}

\subsection{Baseline Environment}

The Baseline environment study consisted of seven experimental sessions. Four of the experimental sessions were conducted at the California Institute of Technology (CIT). We call those sessions BCIT1, BCIT2, BCIT3, and BCIT4. Two sessions, BSU1, and BSU2, were conducted at Sofia University (SU), Bulgaria. The last session within the Baseline environment, called BUSLA, was conducted at UCLA.

All subjects in the CIT sessions were Caltech undergraduate students taking introductory Economics classes. A large majority of the participants at Sofia University were students either in the Department of Mathematics and Informatics, or in the Department of Physics of SU. The rest were students from other departments of SU or other universities in Sofia, Bulgaria. The participants at the UCLA site

\footnotetext{
${ }^{17}$ Each cell of the payoff table of the sellers consists of four entries. The payoff from a transaction with a Red buyer is given in the upper left corner of each cell (in red), while with a Blue buyer is in the upper right corner (in blue). In parenthesis are the corresponding buyers' payoffs.
} 
were students enrolled for the 2002 Summer term at UCLA. The summary of the Baseline sessions is presented in Table 1. Some of the students at the CIT and UCLA sites had had previous experience with experiments in Economics (as they were registered in the experimental databases at their institutions). For all students at Sofia University it was their first time participating in experiments.

The sessions BCIT1, BCIT2, BSU1, and BSU2 were organized as open outcry markets. The rest were organized as computerized markets. In the manually run sessions, if a seller wanted to send a sell order to the market, she had to raise her ID number, announce the market, the price, as well as the number of units she wanted to offer at this market and price. Buyers could only accept offers. In order to accept an offer, a buyer had to raise his ID number, and announce the market and the price of the offer he wanted to accept. In the manually conducted experiments the book was organized in chronological order. When a buy order came, the contract that was sold first was the one that was offered first.

In the computerized experiments a lender was picked at random when a given contract was offered by more than one lender 18 The lenders could submit their offers by clicking on any number of the cells of the trading screen (like the one presented in Figure 4). Each click sent one offer to the market. Entrepreneurs could accept any one of the outstanding offers by clicking on the corresponding cell 19 In the manual experiments a table similar to the trading screen in Figure 4 was drawn or projected on the board and all orders were recorded by the experimenter as soon as they were made in the corresponding cells. Table 2 presents the exchange rates for the seven sessions as well as the average payoffs for the lenders and the entrepreneurs ${ }^{20}$

Both the oral and computerized sessions started with the experimenter reading out loud the instructions. Each session then proceeded with a practice period that lasted 10 minutes for the computerized sessions and 15 minutes for the oral sessions. During the practice period participants could privately ask questions. After the practice session there was a break in which participants could ask questions in private. The actual periods started only after there were no more questions from the participants.

\footnotetext{
${ }^{18}$ With the time preference rule, at the pilot for the computerized sessions, the subjects always tried to submit orders in the first several seconds of each period causing the web-server to crash. This induced the switching to the random order rule.

${ }^{19}$ Instructions and screens for the experiments can be viewed at http://eeps4.caltech.edu/market-020919. Use identification ID:1 and password:a to login as a viewer. As a viewer you will not have a payoff but you will be able to see the trading screen as well as all the forms.

${ }^{20}$ At the time the experiments were run, the exchange rate between US dollars and Bulgarian levs was 2.11 levs per dollar. According to the estimate of the Bulgarian "Podkrepa" Labor Confederation, at this time, people with minimum wage in Bulgaria disposed of USD 1.08 per day, while for those with medium wage the amount was USD 3.80 per day.
} 


\subsection{Non-Existence Environment}

This part of the experimental study differed from the previous one only in the discretization of the contract space. Among the contracts included in the grid of contracts were several pairs that Pareto-dominate the equilibrium-in-single-contracts pair of contracts.

Six sessions were run within the Non-existence environment. Five of the sessions were conducted at UCLA, and are called NUSLA1, NUSLA2, NUSLA3, NUSLA4, and NUCLA5. One session was conducted at CIT, and is called NCIT. The participants in the first four UCLA session were students enrolled at UCLA for the 2002 Summer term. Those in NUCLA5 were enrolled in the 2004 Summer term. The participants at the CIT site were all Caltech students. Since the experiments were conducted during the summer, the Caltech students were not enrolled in any classes at that time.

All experiments within this environment were computerized 21 All sessions had 23 participants: six lenders, and seventeen entrepreneurs. In all sessions nine of the entrepreneurs were high-risk and eight were low-risk type (i.e., $\lambda$ was equal to $9 / 17$ in all sessions). This information is summarized in Table 3 . The procedures regarding the practice period and the Q\&A session were the same as in the Baseline treatment. Following the practice period, there were fourteen periods in each session. Table 4 presents the exchange rates as well as the average payoffs for the lenders and the entrepreneurs in the Non-existence sessions.

\section{Conjectures}

The parametrization of the model described in section 3.1 is used to formulate a number of conjectures, to be tested empirically later on.

The Baseline treatment is designed around the theoretically non-controversial setup where the RS equilibrium in single contracts exists, is Pareto-optimal, and consequently coincides with the equilibrium in menus of contracts. The equilibrium contracts offered and chosen separate the entrepreneurs by risk type; lenders make zero profits on each of those contracts.

The basic predictions from the theoretical model in the Baseline environment are tested in two steps. The prediction that the contracts offered by the lenders will separate the entrepreneurs by their type leads to the first conjecture.

\footnotetext{
${ }^{21}$ Instructions and screens for the experiments can be viewed at http://eeps4.caltech.edu/market-020917. Use identification:1 and password:a to login as a viewer.
} 
Conjecture (A) The entrepreneurs can be separated by their risk type based on the loan contracts they take. High-risk entrepreneurs take bigger loans and bear higher credit spreads than the low-risk entrepreneurs.

Further, the model predicts that from all separating contracts the zero-profit Pareto-optimal ones emerge in equilibrium. The next conjecture concerns this implication.

Conjecture (B) Lenders make zero expected profits on every contract they offer.

The underlying theory will be confirmed if Conjectures (A) and (B) hold in the Baseline environment.

The Non-existence treatment is designed to investigate the outcome in a competitive environment when the competitive equilibrium does not exist. More specifically, the questions being asked are whether markets stabilize around any particular contracts, whether those contracts provide separation of entrepreneurs by risk type, and finally whether a Pareto-optimal allocation is attained. Two plausible candidates for "stable" menus of contracts are the RS candidate for equilibrium pair and the pair of Pareto-optimal contracts. The following conjecture addresses the possibility that the market settles on one of those alternative pairs.

Conjecture (C) The entrepreneurs can be separated by their risk type based on the loan contracts they take. High-risk entrepreneurs take bigger loans and bear higher credit spreads than the low-risk entrepreneurs. Moreover, one of $(\mathrm{Ca})$ or $(\mathrm{Cb})$ holds.

(Ca) The contracts traded stabilize around the equilibrium-in-single-contracts pair.

(Cb) The contracts traded stabilize around the Pareto-optimal pair, which involves cross-subsidization.

The emergence of any of the above outcomes would provide a rejection of the Nash conjecture that underlies the notion equilibrium in menus of contracts. Investigating further what forms of beliefs bring about the outcomes in the experiments, however, is beyond the scope of this paper. (Ca) is a theoretical possibility if the lenders hold instead of the Nash conjecture, the Riley conjecture (see Riley (1979a)). $(\mathrm{Cb})$ would obtain in equilibrium in menus of contracts if the lenders hold the Wilson conjecture (see Miyazaki (1977)). A good discussion about the above conjectures is provided in Riley (1979b).

The last conjecture addresses the possibility that separation fails altogether.

Conjecture (D) The contracts traded cannot be used to separate the entrepreneurs by their risk type. 


\section{$7 \quad$ Results}

\subsection{Data}

The empirical analysis that follows uses the experimental transactions data. For each transaction there is a record including a time stamp, the ID of the lender, and the ID and the type (high-risk or low-risk) of the entrepreneur. The subsections below present the experimental results by treatment.

\subsection{Baseline Environment}

There were 945 transactions within the seven Baseline sessions, just below the maximum possible of 971 (which would obtain if each entrepreneur enters into a contract in every trading period). Figure 5 (a) presents the two-dimensional histogram of all trades in the Baseline sessions ${ }^{22}$ One simple observation is that the trades are clustered into two classes, one with high high face value $(\alpha)$ and high credit spread $(\beta)$ contracts, and the other with low $\alpha$ and $\beta$. Further inspection shows that the most traded contracts are $(\alpha, \beta)=\{(100,78),(95,74),(23,14),(34,23)\}$ with frequencies $222,122,98$, and 72 respectively. The first two are the equilibrium contracts designed for the high-risk agents. Both contracts provide the highrisk entrepreneurs with a payoff of 80 . Low-risk entrepreneurs have strictly negative payoffs from those contracts. The lenders' corresponding payoffs are 2 and 1 , the lowest non-negative payoffs. The other contract in the (Pareto-optimal) equilibrium menu of contracts is $(\alpha, \beta)=(23,13)$. Low-risk agents' payoff is 89 from the equilibrium contract designed for them, while the lenders get 2 if the contract is indeed undertaken by a low-risk entrepreneur. The high-risk agents have a payoff of 80 from this contract which makes them exactly indifferent between the equilibrium contracts designed for the two types of entrepreneurs. If a high-risk entrepreneur, however, resolves the indifference between the two types of contract in favor of $(23,13)$, the resulting payoff for the lender is strictly negative. Instead of the equilibrium contract, the two most frequently offered contracts targeting the low-risk entrepreneurs were ones providing slightly lower payoffs to both types of entrepreneurs (thus circumventing the highrisk agents' indifference issue) and small positive profits for the lenders when contracting with low-risk agents. The contract $(\alpha, \beta)=(23,14)$, for instance, paid off 76 and 72 to the low- and high-risk agents

\footnotetext{
${ }^{22}$ The transaction histograms for both the Baseline and the Non-existence treatments are presented using the same grid which includes all possible contracts $(\alpha, \beta)$ used in the two treatments.
} 
correspondingly. The lenders' profit was 12 . This finding is discussed in more detail further down in this section.

To formally test conjecture (A), we first test the null hypothesis that the transactions data come from a bivariate (normal) distribution versus the alternative that the data come from a mixture of two bivariate (normal) distributions, i.e.,

$$
\begin{gathered}
H_{0}:(\alpha, \beta) \sim N\left(\mu_{0}, \Sigma_{0}\right) \\
\text { vs. } \\
H_{1}:(\alpha, \beta) \sim(1-\theta) N\left(\mu_{1}, \Sigma\right)+\theta N\left(\mu_{2}, \Sigma\right),
\end{gathered}
$$

where $\mu_{i}=\left(\mu_{i \alpha}, \mu_{i \beta}\right), i=1,2$.

The null hypothesis (one-class model) can be rejected in favor of the alternative (two-class model) at the $95 \%$ confidence level (with a p-value of less than 0.001) ${ }^{23}$ Using the two-class model, the traded contracts that fall in Class 1 are presented in Figure 5 (b), while the ones that fall in Class 2 are presented in Figure 5 (c). If the theoretical predictions of the model hold, so that the contracts offered and chosen indeed separate the entrepreneurs by types, the estimate of the mixture parameter $\theta$ should not be significantly different than $\bar{\lambda}$, the proportion of high-risk entrepreneurs in the Baseline sessions. The mixture parameter estimate is $\hat{\theta}=0.5545$. The $95 \%$ confidence interval for the parameter $\theta$ is $(0.5226,0.5865)$, and $\bar{\lambda}=0.5581$ falls in it.

The above analysis clearly shows that the data is separated into two classes. Moreover, the data is split between the two classes in the right proportions. However, it remains to show that the classes are homogeneous, i.e., one is consisting mainly of transactions with high-risk entrepreneurs while the other of transactions with the low-risk ones. Table 5 shows the cross-tabulation by buyers' types as well as the estimators of the mean parameters for the two classes. $86 \%$ of the transactions in Class 1 involve low-risk entrepreneurs, while in Class 2 the contracts with high-risk entrepreneurs constitute $90 \%$ of all trades. The histogram of all contracts between lenders and low-risk entrepreneurs is presented in Figure 5 (d), while the contracts with high-risk entrepreneurs are presented in Figure 5 (e). Overall, the above results provide strong support for conjecture (A).

\footnotetext{
${ }^{23}$ Since $\theta=0$ is a boundary case, the statistic in the likelihood ratio test is no longer distributed as chi-square. The distribution of the statistic is presented in Zhu and Zhang (2004). The mixture model maximum log likelihood estimates are based on the EM algorithm, which is standard for estimating mixture models.
} 
As it usually takes time for the markets to equilibrate, we perform the above analysis on the data from the last three periods of all Baseline sessions. The histogram of all transactions in the last periods is presented in Figure 6 (a). The separation into two classes is evident from this plot of the data. The hypothesis of one class is rejected in favor of the mixture model at p-level of less than 0.001. The contracts falling in each of the two classes are presented in Figure 6 (b) and Figure 6 (c). The 95\% confidence interval for the parameter $\theta$ is $(0.4603,0.5826)$, and $\bar{\lambda}=0.5581$ falls in it $(\hat{\theta}=0.5215)$. The separation of the entrepreneurs by risk types in the two classes is evident from the results in Table 6 . Lastly, the histogram of trades involving high/low-risk entrepreneurs is presented in Figure 6 (d) and Figure 6 (e). When only the last three periods are considered, from the 132 contracts in Class 2, 122 were among the two equilibrium contracts designed for the high-risk agents. The equilibrium contract for the low-risk entrepreneurs was traded 17 times in the last three periods. The contract that was traded most often was $(\alpha, \beta)=(34,23)$. The results from the the last three periods provide even stronger support for conjecture (A).

Next we turn to testing conjecture (B). Simple inspection of the most frequently traded contracts shows that the contracts with Red traders were mostly on the "high-risk" zero-profit line (as shown on Figure 11. The contracts with Blue buyers were traded slightly below the "low-risk" zero-profit line, i.e., at a profit for the sellers. To test conjecture (B), we test the hypotheses

$$
\begin{array}{cccc}
\left(H l_{0}\right): \quad \mu_{1 \beta}-p_{l} \mu_{1 \alpha}=0 & \text { vs. } \quad\left(H l_{1}\right): \mu_{1 \beta}-p_{l} \mu_{1 \alpha} \neq 0 \\
& \text { and } \\
\left(H h_{0}\right): \quad \mu_{2 \beta}-p_{h} \mu_{2 \alpha}=0 & \text { vs. } \quad\left(H h_{1}\right): \mu_{2 \beta}-p_{h} \mu_{2 \alpha} \neq 0
\end{array}
$$

$\left(H l_{0}\right)$ states that the mean contract in Class 1 traded on zero profit for the lenders (assuming homogeneity of the classes). The second one, $\left(H h_{0}\right)$ states that the mean contract in Class 2 made zero profits for the lenders. Using all periods in the Baseline sessions, $\left(H l_{0}\right)$ is rejected at the $95 \%$ level. The mean profit in Class 1 is 35 francs (t-statistic of 29$)$. $\left(H h_{0}\right)$ is also rejected at the $95 \%$ level. The mean profit in Class 2 is -19 francs (t-statistic of -8.7). Thus, using all data and assuming that Class 1 consists of trades with low-risk entrepreneurs while Class 2 consists of trades with high-risk entrepreneurs, we find that sellers offer money losing contracts to the high-risk entrepreneurs while the contracts offered 
to the low-risk ones are with positive profits ${ }^{24}$ At first this result might seem puzzling, especially in the light that no cross-subsidized contracts were available to the lenders to offer. Instead, the results can be explained by the fact that a fair amount of pooling contracts were offered in the initial periods. Whenever a pooling contract was taken by a low-risk entrepreneur, the lenders made big profits while when high-risk entrepreneurs took it, the lenders made more than offsetting losses. Those pooling contracts are roughly equally split into the two classes, and they positively (negatively) impact the mean in Class 1 (Class 2).

Comparing the histograms of trades in all periods and in the last three periods, it is apparent that pooling contracts are no longer offered in the later periods. The zero profit hypothesis is tested next using the data from the last three periods only. As already discussed, the contracts in Class 2 were essentially the two equilibrium contracts. In Class 1, the lenders offered contracts that were slightly more unfavorable to the entrepreneurs in comparison to the equilibrium contract: the mean characteristics of a contract in Class 1 are $(\alpha, \beta)=(29.7,19.6)$. When hypotheses $\left(H l_{0}\right)$ is tested against $\left(H l_{1}\right)$, and $\left(H h_{0}\right)$ is tested against $\left(H h_{1}\right),\left(H l_{0}\right)$ is still rejected in favor of $\left(H l_{1}\right)$. The mean profit in Class 1 is 30 (t-statistic of 14.9). $\left(H h_{0}\right)$ cannot be rejected at the $95 \%$ confidence level. Thus, the lenders make zero profit on the contracts designed for the high-risk entrepreneurs but they make strictly positive profits on the contracts designed for the low-risk entrepreneurs. This finding can naturally be attributed to the fact that in equilibrium the high-risk entrepreneurs are indifferent between the contracts designed for them and the contract designed for the low-risk agents. If sellers have any doubts that the high-risk entrepreneurs are going to choose the "right" contract when indifferent, they should offer to the low-risk agents a contract at slightly worse terms as to insure that the high-risk ones do not choose it.

Overall, the results from the Baseline environment provide strong support for conjecture (A). The data from the last three periods provides support for conjecture (B) if one accounts for the possible hedging on the side of lenders against the high-risk entrepreneurs choosing the contract designed for the low-risk entrepreneurs when indifferent between the two contracts. However, in the initial periods sellers do offer pooling contracts and this affects the mean profits of the contracts in both Class 1 and Class 2 .

\footnotetext{
${ }^{24}$ If instead of using the separation by classes, we use the actual types of the entrepreneurs (which of course the lenders could not have done), i.e., if we test whether on average the contracts with high-risk agents and the contracts with low-risk agents yield zero profits each for the lenders, we obtain similar results. The mean profit from low-risk entrepreneurs is 36 (t-statistic of 13.4), while the profit from high-risk entrepreneurs is -13 (t-statistic of -7.7).
} 
Also, it is interesting to note that although the average payment in Bulgaria was at least ten times higher in real terms than the average payment in the US, there are no significant differences between the structures of the classes for the two data sets 25

\subsection{Non-existence Environment}

The analysis here mirrors the analysis presented in Section 7.2 . There were 1377 trades in all Nonexistence sessions (the maximum possible was 1428). Figure 7(a) presents the transactions histogram.

As before, the null hypothesis that the data come from a one-class model is tested against the alternative that they are generated by a two-class model. The null is rejected at the $95 \%$ confidence level with a p-value of less than 0.001 . The contracts that fall in the two classes are presented in Figures 7 (b) and 7 (c) respectively.

The proportion of high-risk entrepreneurs in this environment was $\lambda=9 / 17$. Separation of trades by risk types requires that the traded contracts be split between the two classes in relative proportions equal those of high to low-risk entrepreneurs. If separation holds, the mixture parameter $\theta$ should not be significantly different from $9 / 17$. The estimate of the mixture parameter is $\hat{\theta}=0.36$. The $95 \%$ confidence interval for $\theta$ is $(0.309,0.4111)$ and $\lambda=9 / 17$ is well beyond this interval. Thus, at this stage, an econometrician who knows the proportion of the high-risk entrepreneurs and the contracts that were traded in the market will be able to reject the hypothesis that the contracts offered and chosen separate the entrepreneurs by their risk types. However, an econometrician who does not know the true proportions (as is the case in the real world) but is instead estimating them from data while not able to

\footnotetext{
${ }^{25}$ When the analysis of this section is performed separately on the last three periods of data from Bulgaria (BSU1 and BSU2) and from the two corresponding manually conducted experiments in the US (BCIT1 and BCIT2) the hypothesis that the data come from one class model is rejected in favor of the two class alternative for both data sets. The mixture parameter estimates for Bulgaria and the US are equal to 0.5322 and 0.6111 , both not significantly different from their theoretically predicted values of 0.5455 and 0.5556 correspondingly. The mean contracts in Class 2 are not significantly different for the two populations, and equal to $(98.3,76.6)$ and $(99.8,75.4)$. The mean contracts in Class 1 , however, are different for the two populations. The mean contract targeting the low-risk entrepreneurs in Bulgaria was (39.3, 23.2) while that in the US was $(23.5,13.9)$. The latter is very close to the equilibrium prediction while the former is a contract that entails profit if undertaken by a low-risk entrepreneur and more than offsetting loss if undertaken by a high-risk entrepreneur. Careful examination of Class 1 contracts in Bulgaria shows that the most frequently traded contracts were the equilibrium contract $(23,13)$, and $(23,14)$ and $(34,23)$, the latter providing slightly worse terms to the entrepreneurs in comparison to $(23,13)$. Several pooling contracts of the type described above were offered even in the last periods, however. Because of the small sample size those contracts have an impact on the mean in this class.
} 
reject that separation holds, will wrongly get $\hat{\lambda}=0.36$. Figures 7 (d) and 7 (e) present the transactions histograms for each of the entrepreneurs' types. The cross-tabulation within the two classes is shown in Table 7. Of course, given the relative proportions of the two classes, it is not surprising that more than half of the contracts accepted by high-risk entrepreneurs belong to Class 1 instead to Class 2 .

Thus, when the data from all periods is used, neither conjecture $(\mathrm{Ca})$ nor $(\mathrm{Cb})$ holds as both of them require separation of trades by types. As a result conjecture (D) is supported.

When the data from the last three periods only is used, the one-class model is rejected in favor of the two-class model with a mixture parameter of $\hat{\theta}=0.3$. The $95 \%$ confidence interval for $\theta$ does not contain $9 / 17$ and thus separation of types is rejected in the last three periods as well. The histograms for the two classes are in Figure 8 (b) and Figure 8 (c). The cross-tabulation within the two classes by risk types is presented in Table 8. Figure 8 (d) and Figure 8 (e) show the three-dimensional histograms for transactions with low- and high-risk entrepreneurs correspondingly. Overall, the results from the last three periods of the Non-existence sessions fail to provide support for either (Ca) or (Cd) (and thus provide support for conjecture (D)).

When performed session by session, the above analysis shows that in three of sessions, namely NUCLA2, NUCLA4, and NCIT, the contracts traded separate the buyers by type. The estimation of the two-class model on the aggregate data from those three sessions results in a mixture parameter estimate of 0.5145 . The $95 \%$ confidence interval for this parameter is $(0.4758,0.5532)$, and $9 / 17$ falls in it. Moreover, the cross-tabulation of risk types in the two classes shows that roughly $90 \%$ of the classes have the "right" type of entrepreneurs taking the contracts. The results from the test of zero profits reject the zero-profit hypothesis for both classes. The mean profit in Class 1 is 45 francs, while the mean profit in Class 2 is 3.9 francs. In the last three periods the corresponding profits are 35 and 0 . These results are very similar to the ones for the Baseline sessions.

In contrast, the rest of the sessions (NUCLA1, NUCLA3, and NUCLA5) fail to exhibit separation by risk types in the two classes of contracts. Cross-subsidized pairs of contracts are temporarily traded in those markets, with the clearest example of that ocurring in session NUCLA3. The history of trades for this session (as shown to the subjects on the "History" screen during the session) is presented in Figure 11. The contracts of interest are called E6 and N20, and those are offered in period 6. Contract N20 pays 91 to the high-risk entrepreneurs and -11 to the lenders (the low-risk entrepreneurs' payoff is negative). Contract E6 has a payoff of 78 to the low-risk entrepreneurs, and 34 for the lenders if they transact with low-risk entrepreneurs. The corresponding payoff for the high-risk agents and the lenders are 85 and -41 . 
Thus, each lender who offers the pair and expects that the proportion of N20 contracts from all accepted contracts is equal to the proportion of high-risk entrepreneurs will make a small positive expected profit. In the next period instead of N20, one of the lenders "undercuts" and offers E6 and L15, where L15 provides 113 to the high-risk entrepreneurs and -41 to the lenders. This pair of contracts generates a small negative expected payoff for the lenders (of -6). By periods 9 and 10, however, the money-losing contracts are entirely withdrawn from the market and this results in disproportionately more high-risk entrepreneurs taking E6. Of course, if both types take E6, this contract generates negative expected profit. In response to that, a cross-subsidized pair is offered once again in the next period, where E6 is paired with O23. O23 provides 87 to the high-risk entrepreneurs and -7 to the lenders. Following the next two periods, the money-losing contract is once again withdrawn from the market, sending almost all high-risk entrepreneurs to E6. When this happens the lenders offering E6 lose money in expectation. A question that this study leaves unanswered is whether this cycling would continue for many more periods, or if lenders learn and stop dropping the losing contract from their menus. The issue is left for future investigation.

Overall, in those three sessions, out of the 696 contracts traded, 220 were from cross-subsidizing pairs. However, instead being split roughly 8:9 between contracts intended for low and high-risk entrepreneurs, 177 were contracts that would go to the low-risk agents if the pair were offered (and therefore make positive profits), and only 43 were from the ones intended for the high-risk agents. The latter shows

that many sellers offer only the profit-making contract of the pair of cross-subsidized contracts. This, of course, makes sellers who apply cross-subsidization lose money on average, and they quickly withdraw the money-losing contracts from the market.

Thus in the Non-existence session conjecture $(\mathrm{Cb})$ is unambiguously rejected. The markets do not stabilize around any of the Pareto-optimal pairs of contracts. Separation by risk types fails in sessions NUCLA1, NUCLA3, and NUCLA5, providing mixed support for Conjecture D. Conjecture (Ca) also receives mixed support as in the other three of the sessions separation of trades by types is observed.

\section{Implications for Field Econometric Work and Concluding Remarks}

This paper examines the competitive provision of loans in markets with adverse selection. The notion of equilibrium used is a simple extension of the RS equilibrium to allow for multiple contracts to be offered 
by any single lender. Equilibrium in this framework exists if and only if the candidates for RS equilibrium contracts provide a Pareto-optimal allocation.

The model is first tested in a Baseline scenario in which the equilibrium in menus of contracts exists. The results from this treatment illustrate that the contracts traded are clearly separated into two classes, with the high-risk entrepreneurs undertaking bigger loans and bearing higher credit spreads than the low-risk entrepreneurs. Profits are zero for contracts with high-risk entrepreneurs and positive for contracts with low-risk entrepreneurs. Lenders seem be to offering less attractive contracts to the lowrisk clients than equilibrium would predict to prevent the high-risk entrepreneurs from also undertaking them. Overall, the results from the Baseline sessions provide strong support for the theory.

Next, the model is tested in a setup where the equilibrium in menus of contracts does not exist. In three of those sessions separation occurs and the zero-profit hypothesis cannot be rejected for the contracts offered to the high-risk entrepreneurs. In the other three sessions temporary cross-subsidization is observed but markets never stabilize. The contracts traded in those sessions are still clearly separated into two classes. However, the classes are not homogeneous as separation of contracts by risk types would require. Thus, separation by risk types is rejected only because of the experimenter's knowledge of the types of entrepreneurs undertaking the contracts in each of the two classes. This implies that fitting the standard model to field data may lead to serious biases in estimated parameters while falsely accepting the model's main restriction (separation).

The findings from the Non-existence sessions imply that in competitive framework where the lenders offer the loan terms, the separating contracts studied in the corporate finance literature might not be a robust market outcome. It is left for future research to investigate the market conditions and dynamics leading to each of the possible outcomes.

\section{References}

Akerlof, George, 1970, The Market for 'Lemons' : Quality Uncertainty and the Market Mechanism, QJE, $89,488-500$.

Ania, Ana B., Thomas Troger, and Achim Wambach, 2002, An Evolutionary Analysis of Insurance Markets with Adverse Selection, Games and Economic Behavior, 40, 153-184. 
Bossaerts, Peter, 2003, Experiments With Financial Markets: Implications For Asset Pricing Theory, Caltech working paper.

Cadsby, Charles B., Murray Frank, and Vojislav Maksimovic, 1990, Pooling, Separating and Semiseparating Equilibria in Financial Markets: Some Experimental Evidence, Review of Financial Studies, 3, 315-342.

Dasgupta, Partha, and Eric Maskin, 1986, The Existence of Equilibrium in Discontinuous Games, II: Applications, Review of Economic Studies, 53, 27-41.

Dubey, Pradeep, and John Geanakoplos, 2002, Competitive Pooling: Rothschild-Stiglitz Reconsidered, Quarterly Journal of Economics, 117(4), 1529-1570.

Goswami, Gautam, Martin Grace, and Michel J. Rebello, 2002, Experimental Evidence on Coverage Choices and Contract Prices in the Market for Corporate Insurance.

Hirota, Masayoshi, Ming Hsu, Charles R. Plott, and Brian Rogers, 2005, Divergence, Closed Cycles and Convergence in Scarf Environments: Experiments in the Dynamics of General Equilibrium Systems, Caltech working paper.

Leland, Hayne E., and David H. Pyle, 1977, Information Asymmetries, Financial Structure and Financial Intermediation, Journal of Finance, 32, 371-387.

Miller, Ross M., and Charles R. Plott, 1985, Product Quality Signaling in Experimental Markets, Econometrica, 53, 837-871.

Miyazaki, Hajime, 1977, The Rat Race and Internal Labor Markets, Bell Journal of Economics , 8, 394-418.

Posey, Lisa, and Abdullah Yavas, 2003, Screening Equilibria in Experimental Markets.

Riley, John, 1979a, Informational Equilibrium, Econometrica, 47, 331-360.

Riley, John, 1979b, Noncooperative Equilibrium and Market Signalling, American Economic Review, Vol. 69, No. 2, Papers and Proceedings of the Ninety-First Annual Meeting of the American Economic Association. (May, 1979), 303-307. 
Ross, Stephen A., 1977, The Determination of Financial Structure: The Incentive-Signalling Approach, Bell Journal of Economics, 8, 23-40.

Rothschild, Michael, and Joseph Stiglitz, 1976, Equilibrium in Competitive Insurance Markets, Quarterly Journal of Economics, 90, 629-649.

Spence, A. Michael, 1978, Product Differentiation and Consumer Choice in Insurances Markets, Journal of Public Economics, 10, 427-447.

Wilson, Charles A., 1977, A Model of Insurance Markets with Incomplete Information, Journal of Economic Theory, 16, 167-207.

Zhu, Hong-Tu, and Heping Zhang, 2004, Hypothesis testing in mixture regression models, J. R. Statist. Soc. B 66, Part 1, 316 . 


\section{$9 \quad$ Tables and Figures}

Table 1: Summary of the Sessions in the Baseline Environment

\begin{tabular}{ccccccccc}
\hline & $\begin{array}{c}\text { Exp. } \\
\text { Session }\end{array}$ & Date & \#Lenders & $\begin{array}{c}\text { \#High-risk } \\
\text { Entre- } \\
\text { preneurs }\end{array}$ & $\begin{array}{c}\text { \#Low-risk } \\
\text { Entre- } \\
\text { preneurs }\end{array}$ & \#Periods & Computerized \\
\hline 1 & BCIT1 & $5 / 25 / 01$ & 4 & 5 & 4 & $5 / 9$ & 10 & no \\
2 & BCIT2 & $6 / 25 / 01$ & 4 & 5 & 4 & $5 / 9$ & 10 & no \\
3 & BCIT3 & $6 / 3 / 02$ & 6 & 8 & 7 & $8 / 15$ & 11 & yes \\
4 & BCIT4 & $7 / 18 / 02$ & 5 & 9 & 5 & $9 / 14$ & 12 & yes \\
5 & BSU1 & $8 / 17 / 01$ & 6 & 6 & 5 & $6 / 11$ & 10 & no \\
6 & BSU2 & $8 / 18 / 01$ & 6 & 6 & 5 & $6 / 11$ & 10 & no \\
7 & BUCLA & $9 / 19 / 02$ & 6 & 9 & 8 & $9 / 17$ & 14 & yes \\
\hline
\end{tabular}

${ }^{a} \lambda$ is the proportion of high-risk entrepreneurs in the pool of all entrepreneurs. The average proportion of high-risk entrepreneurs in all Baseline sessions is $\bar{\lambda}=0.5581$ 
Table 2: Summary of the Payoffs in the Baseline Environment

\begin{tabular}{ccccccc}
\hline Exp. & $\begin{array}{c}\text { Exchange Rate } \\
\text { Lenders }\end{array}$ & $\begin{array}{c}\text { Exchange Rate } \\
\text { High-risk } \\
\text { Entrepreneurs }\end{array}$ & $\begin{array}{c}\text { Exchange Rate } \\
\text { Low-risk } \\
\text { Entrepreneurs }\end{array}$ & $\begin{array}{c}\text { Average } \\
\text { Payoff } \\
\text { Lenders }\end{array}$ & $\begin{array}{c}\text { Average } \\
\text { Payoff } \\
\text { Entrepreneurs }\end{array}$ \\
\hline 1 & BCIT1 & $\$ 0.05$ & $\$ 0.03$ & $\$ 0.03$ & $\$ 15$ & $\$ 18$ \\
2 & BCIT2 & $\$ 0.05$ & $\$ 0.02$ & $\$ 0.02$ & $\$ 15$ & $\$ 19$ \\
3 & BCIT3 & $\$ 0.10$ & $\$ 0.03$ & $\$ 0.03$ & $\$ 34$ & $\$ 27$ \\
4 & BCIT4 & $\$ 0.10$ & $\$ 0.03$ & $\$ 0.05$ & $\$ 46$ & $\$ 32$ \\
5 & BSU1 & Lv0.10 & Lv0.04 & Lv0.04 & Lv34 & Lv31 \\
6 & BSU2 & Lv0.09 & Lv0.03 & Lv0.03 & Lv34 & Lv26 \\
7 & BUCLA & $\$ 0.04$ & $\$ 0.02$ & $\$ 0.03$ & $\$ 29$ & $\$ 22$ \\
\hline
\end{tabular}


Table 3: Summary of the Sessions in the Non-existence Environment

\begin{tabular}{ccccccccc}
\hline $\begin{array}{c}\text { Exp. } \\
\text { Session }\end{array}$ & Date & \#Lenders & $\begin{array}{c}\text { \#High-risk } \\
\text { Entre- } \\
\text { preneurs }\end{array}$ & $\begin{array}{c}\text { \#Low-risk } \\
\text { Entre- } \\
\text { preneurs }\end{array}$ & $\sqrt{a}$ & \#Periods & Computerized \\
\hline 1 & NUCLA1 & $9 / 5 / 02$ & 6 & 9 & 8 & $9 / 17$ & 14 & yes \\
2 & NUCLA2 & $9 / 9 / 02$ & 6 & 9 & 8 & $9 / 17$ & 14 & yes \\
3 & NUCLA3 & $9 / 11 / 02$ & 6 & 9 & 8 & $9 / 17$ & 14 & yes \\
4 & NUCLA4 & $9 / 17 / 02$ & 6 & 9 & 8 & $9 / 17$ & 14 & yes \\
5 & NUCLA5 & $7 / 13 / 04$ & 6 & 9 & 8 & $9 / 17$ & 14 & yes \\
6 & NCIT6 & $7 / 16 / 04$ & 6 & 9 & 8 & $9 / 17$ & 14 & yes \\
\hline
\end{tabular}

${ }^{a} \lambda$ is the proportion of high-risk entrepreneurs in the pool of all entrepreneurs. The average proportion of high-risk entrepreneurs in all Baseline sessions is $\bar{\lambda}=0.5581$ 
Table 4: Summary of the Payoffs in the Non-existence Environment

\begin{tabular}{ccccccc}
\hline Exp. & $\begin{array}{c}\text { Exchange Rate } \\
\text { Lenders }\end{array}$ & $\begin{array}{c}\text { Exchange Rate } \\
\text { High-risk } \\
\text { Entrepreneurs }\end{array}$ & $\begin{array}{c}\text { Exchange Rate } \\
\text { Low-risk } \\
\text { Entrepreneurs }\end{array}$ & $\begin{array}{c}\text { Average } \\
\text { Payoff } \\
\text { Lenders }\end{array}$ & $\begin{array}{c}\text { Average } \\
\text { Payoff } \\
\text { Entrepreneurs }\end{array}$ \\
\hline 1 & NUCLA1 & $\$ 0.06$ & $\$ 0.02$ & $\$ 0.025$ & $\$ 49$ & $\$ 25$ \\
2 & NUCLA2 & $\$ 0.04$ & $\$ 0.02$ & $\$ 0.03$ & $\$ 35$ & $\$ 27$ \\
3 & NUCLA3 & $\$ 0.04$ & $\$ 0.02$ & $\$ 0.03$ & $\$ 15$ & $\$ 31$ \\
4 & NUCLA4 & $\$ 0.04$ & $\$ 0.02$ & $\$ 0.03$ & $\$ 47$ & $\$ 20$ \\
5 & NUCLA5 & $\$ 0.04$ & $\$ 0.02$ & $\$ 0.03$ & $\$ 27$ & $\$ 29$ \\
6 & NCIT & $\$ 0.04$ & $\$ 0.02$ & $\$ 0.03$ & $\$ 30$ & $\$ 29$ \\
\hline
\end{tabular}


Table 5: Baseline Environment, All Periods: Distribution of Types by Classes

\begin{tabular}{|c|c|c|c|c|}
\hline & $\begin{array}{c}\text { Number of } \\
\text { Low-risk }\end{array}$ & $\begin{array}{c}\text { Number of } \\
\text { High-risk }\end{array}$ & $\hat{\mu}_{i a} a^{a}$ & $\hat{\mu}_{i \beta} b$ \\
\hline & Entrepreneurs & Entrepreneurs & & \\
\hline Class 1 & 360 & 60 & $29.083(0.535)$ & $19.686(0.396)$ \\
\hline Class 2 & 50 & 475 & $93.807(0.473)$ & $71.035(0.466)$ \\
\hline
\end{tabular}

${ }^{a}$ The mean loan repayment in class $i, i=1,2$; Standard errors in the parenthesis.

${ }^{b}$ The mean credit spread in class $i, i=1,2$; Standard errors in the parenthesis. 
Table 6: Baseline Environment, Last Three Periods: Distribution of Types by Classes

\begin{tabular}{lcccc}
\hline & $\begin{array}{c}\text { Number of } \\
\text { Low-risk } \\
\text { Entrepreneurs }\end{array}$ & $\begin{array}{c}\text { Number of } \\
\text { High-risk } \\
\text { Entrepreneurs }\end{array}$ & $\hat{\mu}_{i a}[a$ & $\left.\left.\hat{\mu}_{i \beta}\right|^{b}\right]$ \\
\hline Class 1 & 106 & 16 & $29.730(0.868)$ & $19.558(0.651)$ \\
Class 2 & 5 & 128 & $98.572(0.343)$ & $76.234(0.361)$ \\
\hline
\end{tabular}

${ }^{a}$ The mean loan repayment in class $i, i=1,2$; Standard errors in the parenthesis.

${ }^{b}$ The mean credit spread in class $i, i=1,2$; Standard errors in the parenthesis. 
Table 7: Non-existence Environment, All Periods: Distribution of Types by Classes

\begin{tabular}{lcccc}
\hline & $\begin{array}{c}\text { Number of } \\
\text { Low-risk } \\
\text { Entrepreneurs }\end{array}$ & $\begin{array}{c}\text { Number of } \\
\text { High-risk } \\
\text { Entrepreneurs }\end{array}$ & $\hat{\mu}_{i a} \mid \hat{\mu}_{i}{ }^{b}$ & \\
\hline Class 1 & 607 & 273 & $34.749(1.876)$ & $24.033(1.107)$ \\
Class 2 & 33 & 464 & $93.083(0.525)$ & $71.448(1.006)$ \\
\hline
\end{tabular}

${ }^{a}$ The mean loan repayment in class $i, i=1,2$; Standard errors in the parenthesis.

${ }^{b}$ The mean credit spread in class $i, i=1,2$; Standard errors in the parenthesis. 
Table 8: Non-existence Environment, Last Three Periods: Distribution of Types by Classes

\begin{tabular}{|c|c|c|c|c|}
\hline & $\begin{array}{c}\text { Number of } \\
\text { Low-risk } \\
\text { Entrepreneurs }\end{array}$ & $\begin{array}{c}\text { Number of } \\
\text { High-risk } \\
\text { Entrepreneurs }\end{array}$ & $\hat{\mu}_{i a}{ }^{a}$ & $\hat{\mu}_{i f}{ }^{b}$ \\
\hline Class 1 & 137 & 72 & $34.213(0.560)$ & $22.625(0.375)$ \\
\hline Class 2 & 4 & 84 & $95.966(0.957)$ & $74.174(0.811)$ \\
\hline
\end{tabular}

${ }^{a}$ The mean loan repayment in class $i, i=1,2$; Standard errors in the parenthesis.

${ }^{b}$ The mean credit spread in class $i, i=1,2$; Standard errors in the parenthesis. 


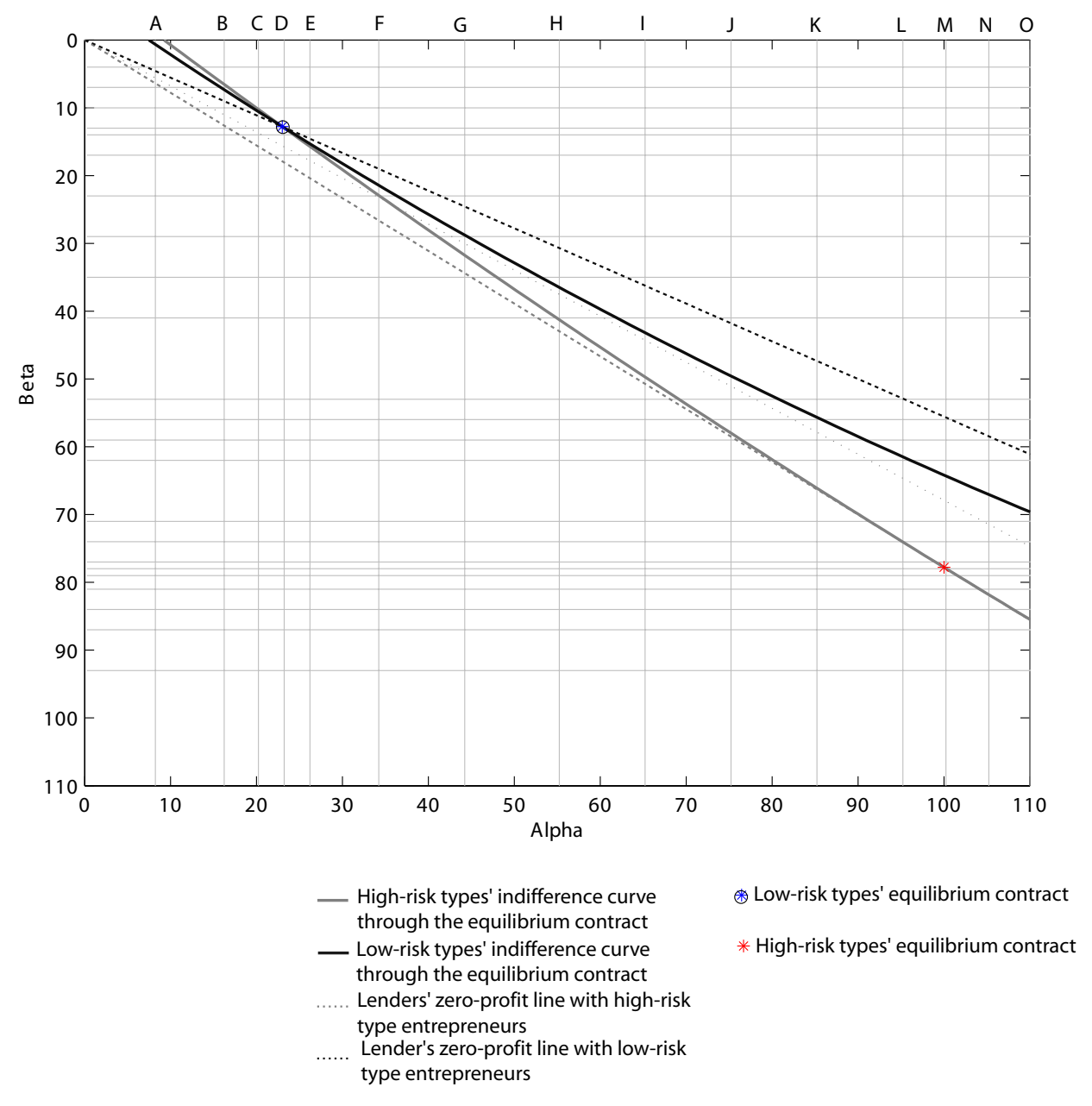

Figure 1: Baseline Environment: The Discrete Grid of Contracts 


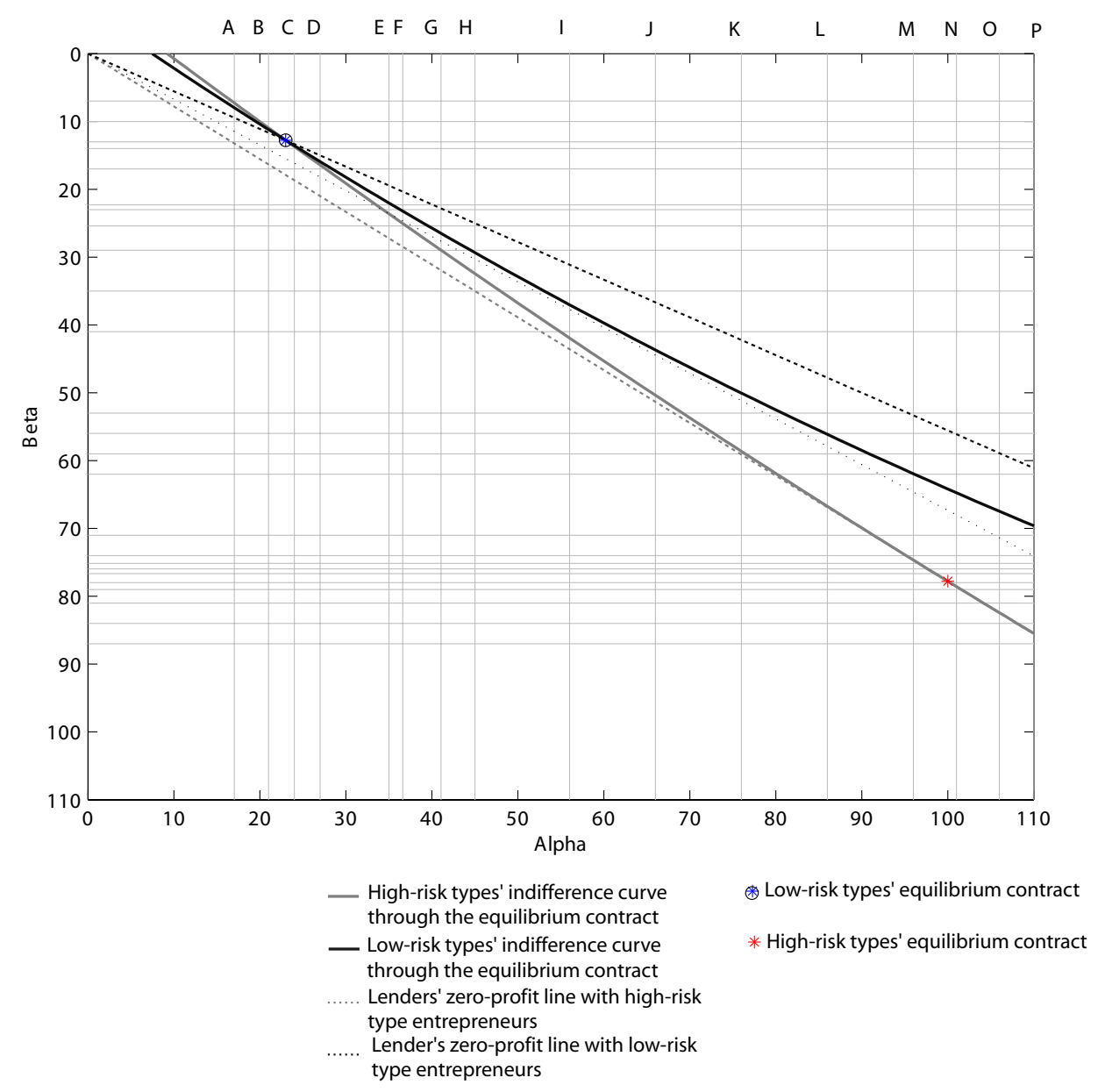

Figure 2: Non-existence Environment: The Discrete Grid of Contracts 


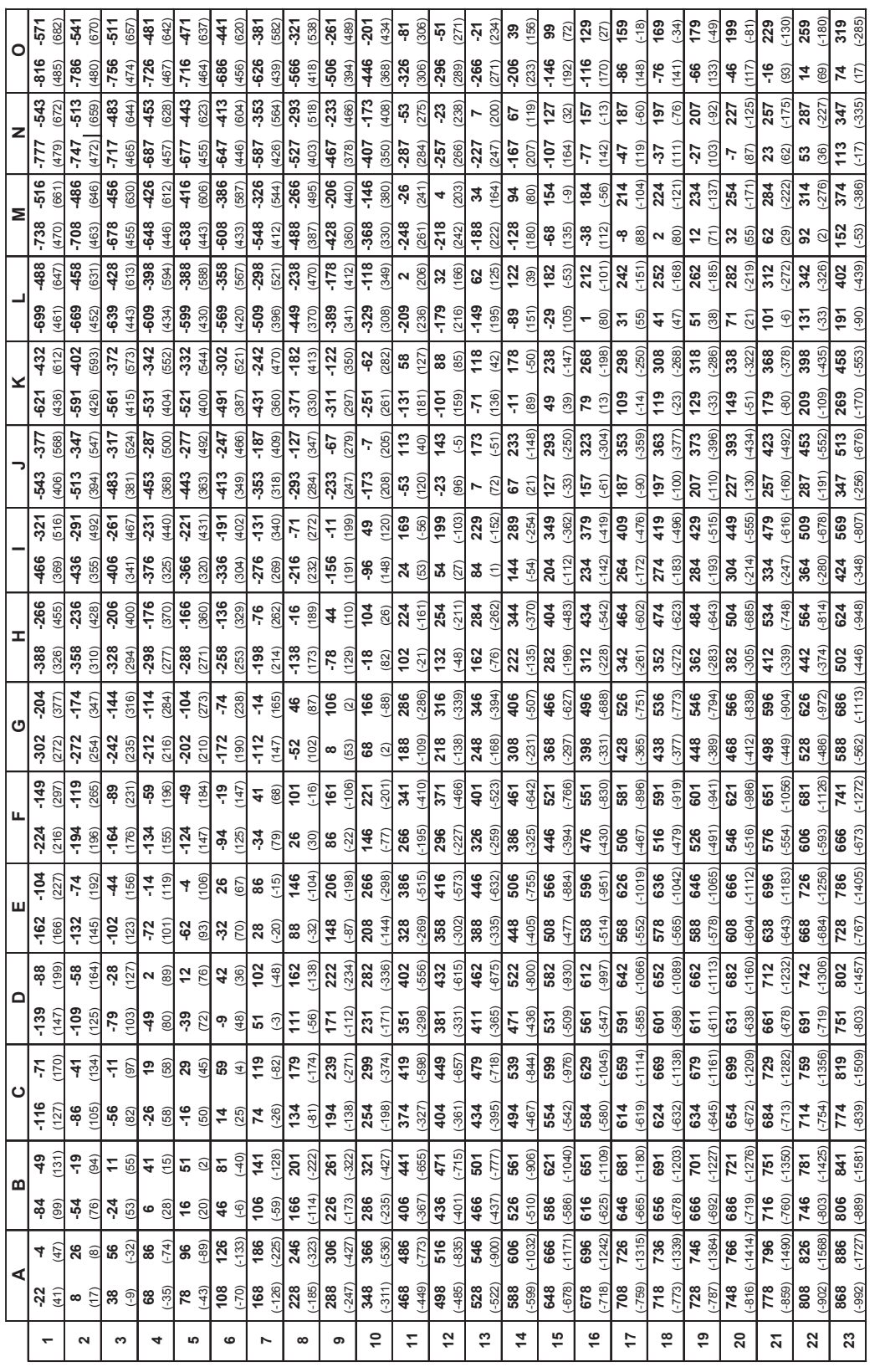

Figure 3: Baseline Environment: The Payoff Table for the Low-risk Entrepreneurs

Each cell of the payoff table of the lenders consists of four entries. The payoff from a transaction with high-risk agents is given in the upper left corner of each cell, while with low-risk agents is in the upper right corner. In parenthesis, beneath the lenders' possible payoffs are the corresponding entrepreneurs' payoffs. 


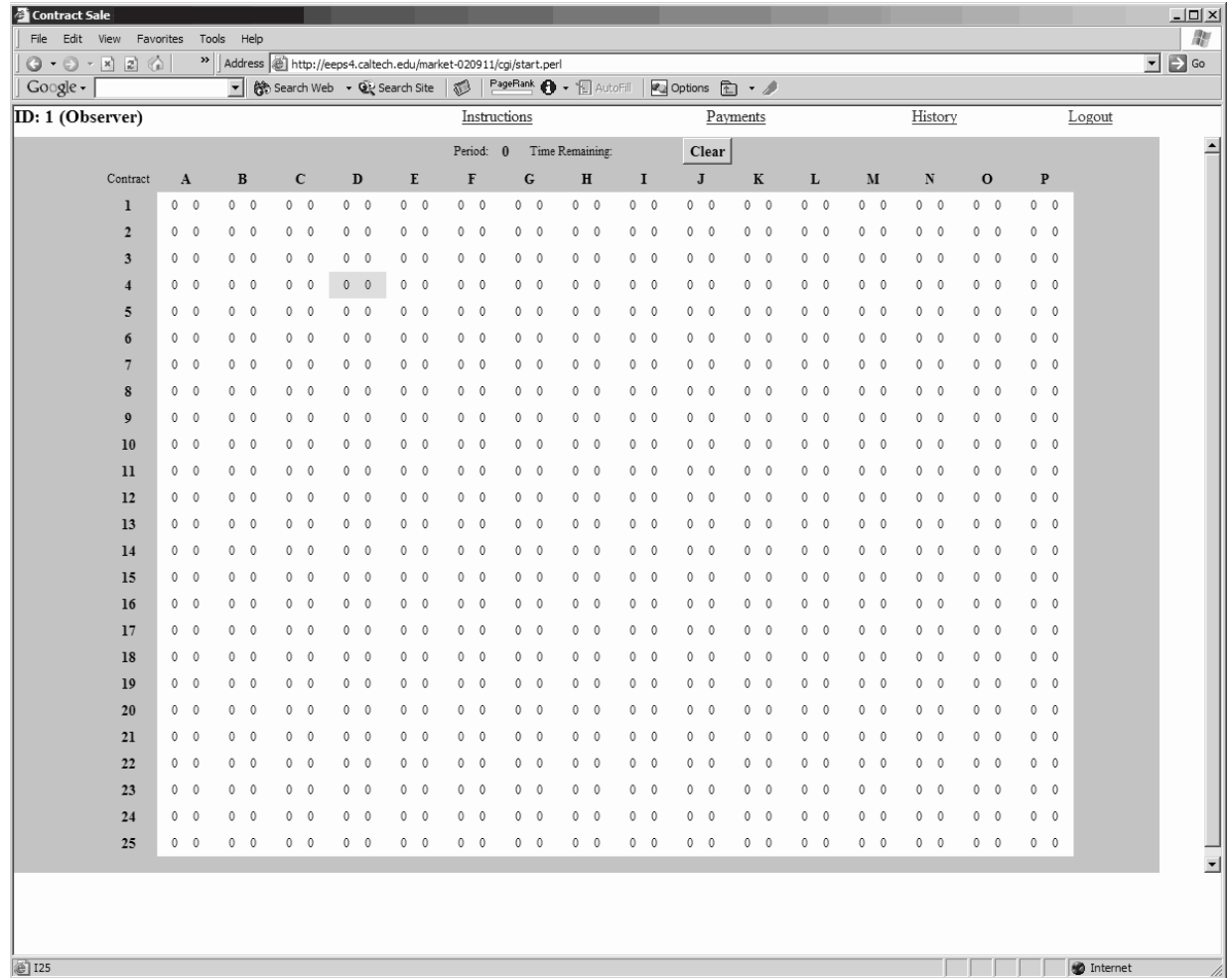

Figure 4: Non-existence Environment: The Trading Screen 


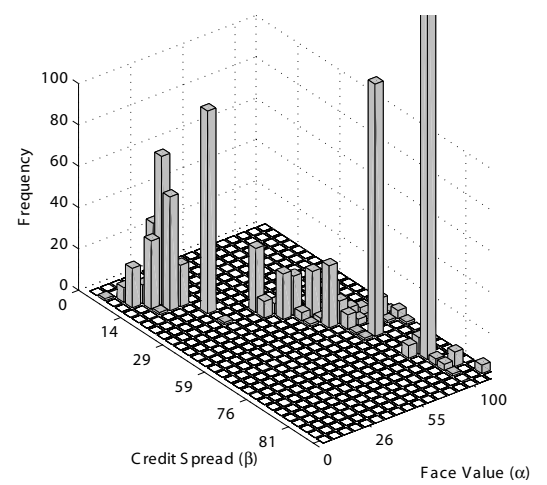

a. Histogram of all trades.

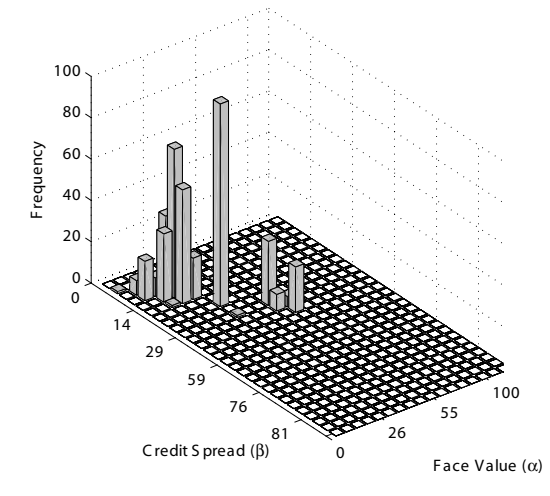

b. Trades in Class 1

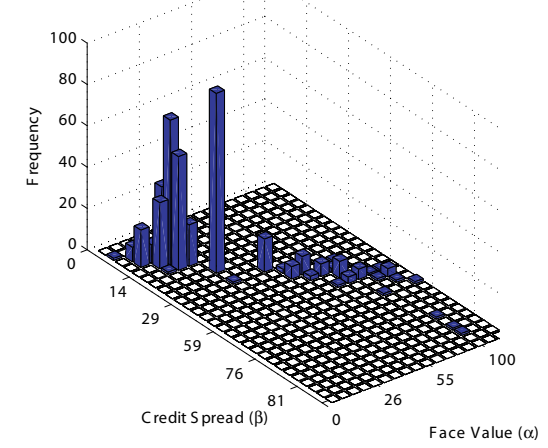

d. Low-risk Entrepreneurs' Trades

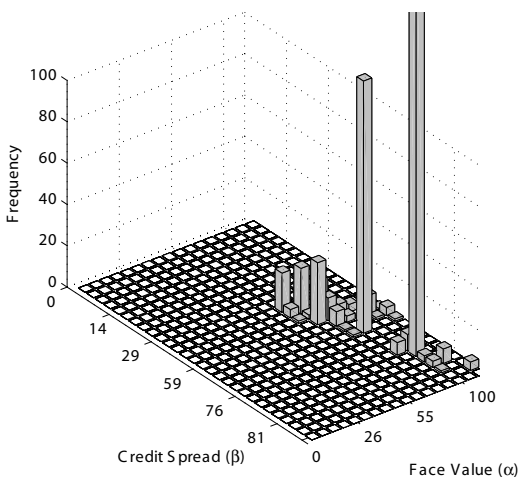

c. Trades in Class 2

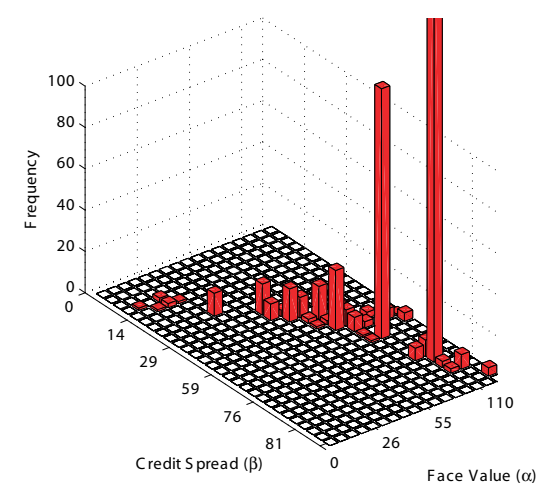

e. Low-risk Entrepreneurs' Trades

Figure 5: Histograms for the Baseline Treatment, All Periods 


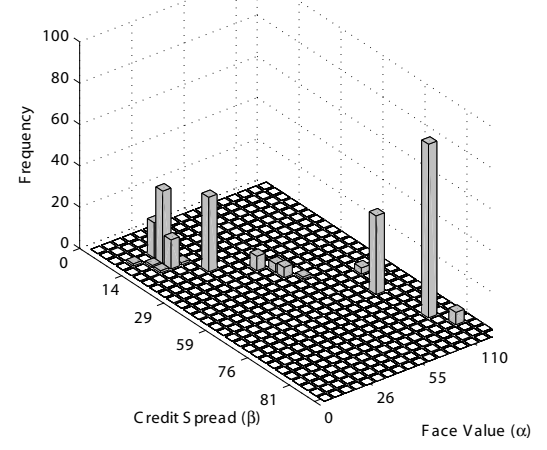

a. Histogram of all trades.

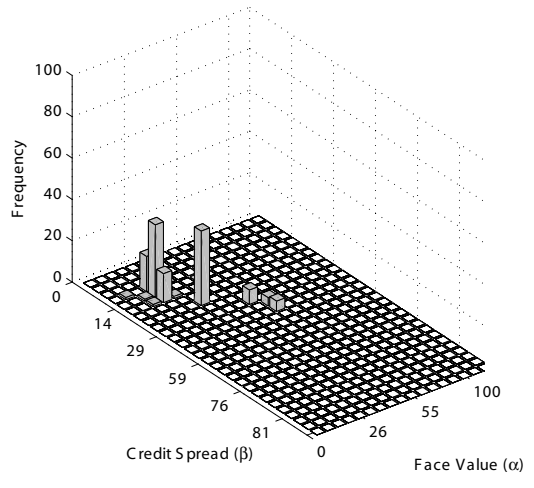

b. Trades in Class 1

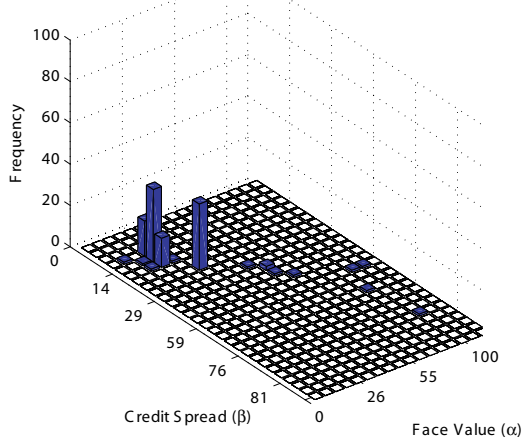

d. Low-risk Entrepreneurs' Trades

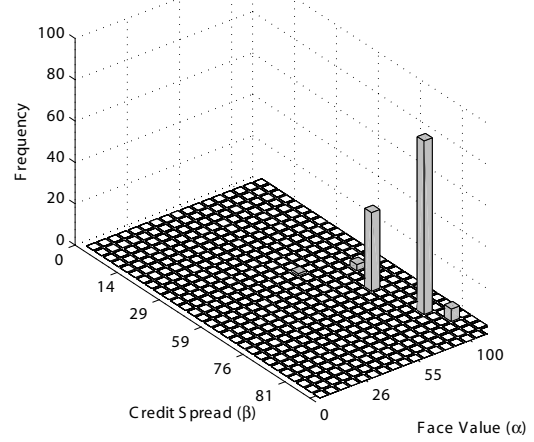

c. Trades in Class 2

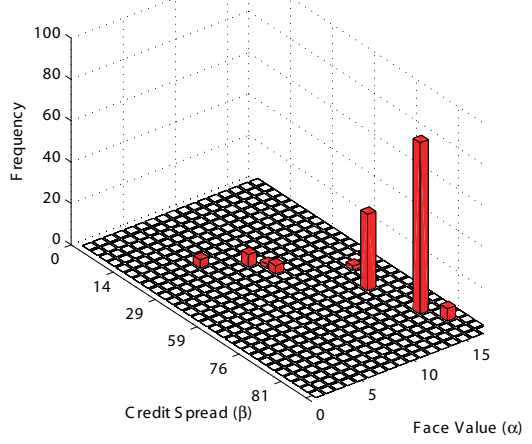

e. Low-risk Entrepreneurs' Trades

Figure 6: Histograms for the Baseline Treatment, Last Three Periods 


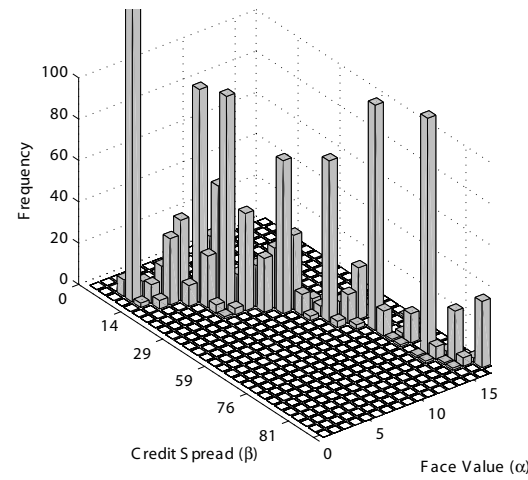

a. Histogram of all trades.

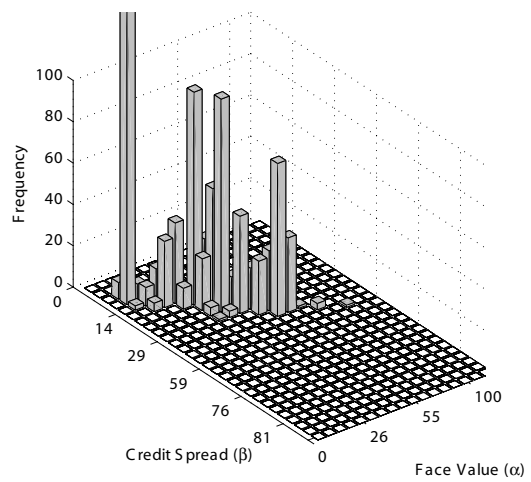

b. Trades in Class 1

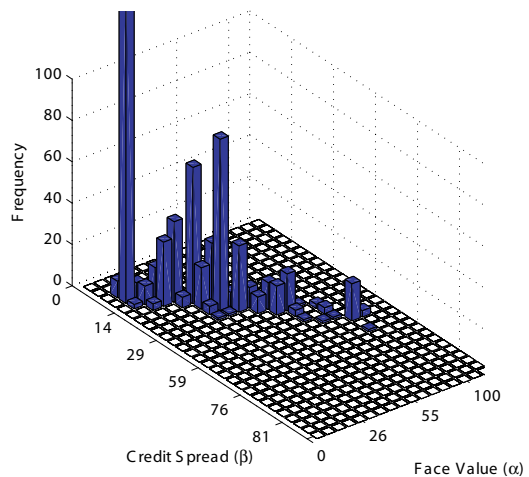

d. Low-risk Entrepreneurs' Trades

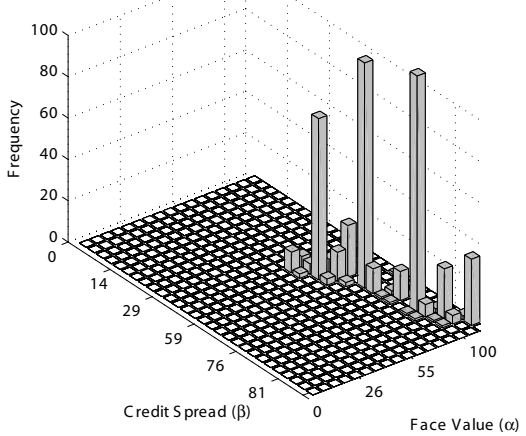

c. Trades in Class 2

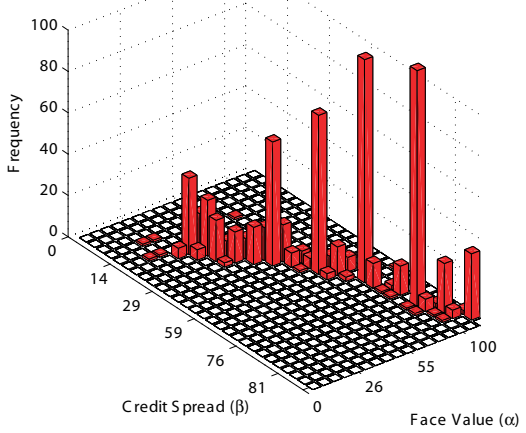

e. Low-risk Entrepreneurs' Trades

Figure 7: Histograms for the Non-existence Treatment, All Periods 


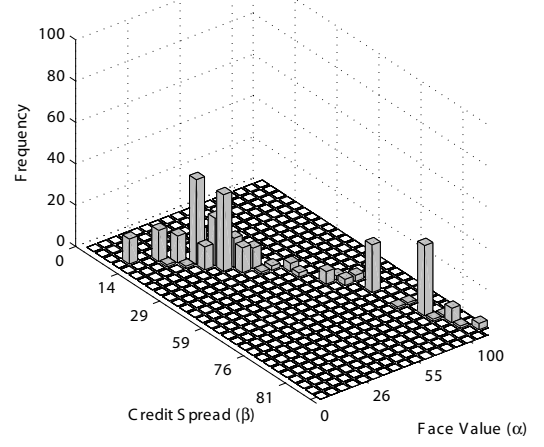

a. Histogram of all trades.

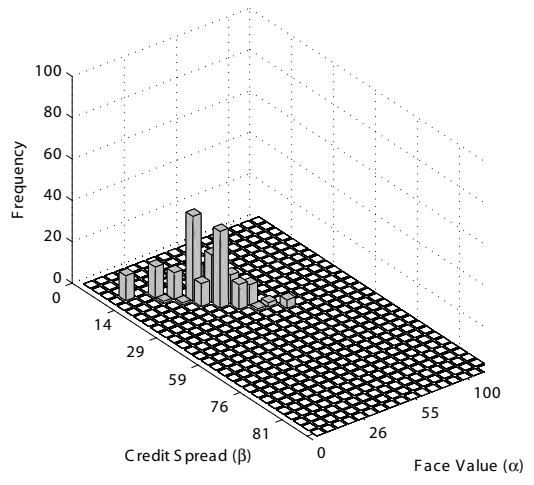

b. Trades in Class 1

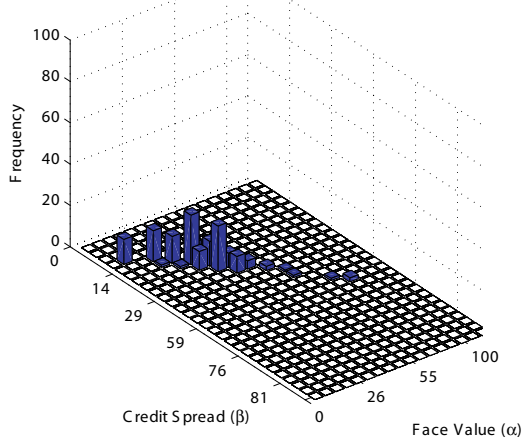

d. Low-risk Entrepreneurs' Trades

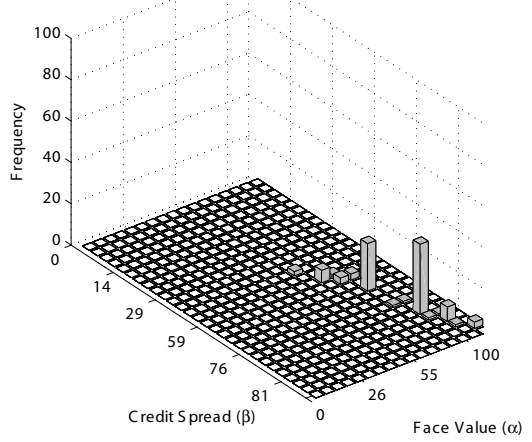

c. Trades in Class 2

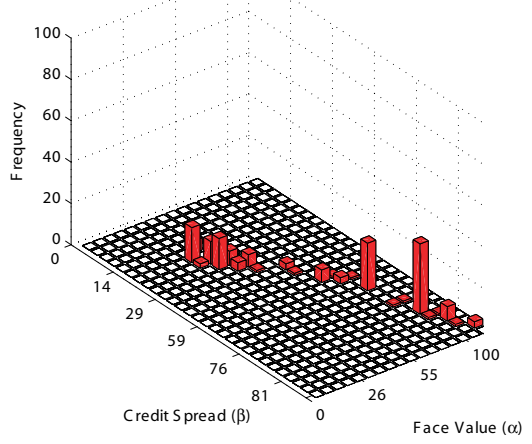

e. Low-risk Entrepreneurs' Trades

Figure 8: Histograms for the Non-existence Treatment, All Periods 


\section{Instructions}

I.Market setup and how to make money There are fifteen markets in this experiment. All fifteen markets involve securities referred to as A, B, C, D, E, F, G, H, I, J, K, L, M, N, and O.

The markets are going to be conducted in 10 to 15 periods. Periods will last around 5 minutes each. You will be told before each period how long this period will be. We will have one practice period before starting the actual ones. The payoff from the practice period WILL NOT be added to your total payoff for the experiment. In each period all fifteen markets are operating. The currency that is used in all markets is called "francs".

Your actions in a given period influence your payoff for that period ONLY. After a period is finished you realize your payoff and a new period is initiated. Your total earnings in the end of the experiment are the sum of your earnings across periods. You can check your earnings at any time by clicking on the link HISTORY on the trading screen.

The participants in the market are divided into two groups: sellers and buyers. Whether you are going to be a seller or a buyer is going to be determined in the beginning of the experiment and it WILL NOT change until the end of it. You can find out whether you are a buyer or a seller by clicking on the "Participate in the Sale" link. The information is in the upper left corner of the screen. The description of the role of each participant in the market follows (we are going to refer to any buyer as "he", and to any seller as "she"):

-Buyers: There are two types of buyers referred to as RED type and BLUE type. In each period there are 9 RED buyers and 8 BLUE buyers, and these numbers do not change across periods. Every buyer will be able to see his type on the announcement board in the bottom of the screen. Please, DO NOT hit the reload button at any time otherwise you will lose important information on the message board.

Buyers can only BUY securities. Each buyer is allowed to buy AT MOST ONE security per period. (Note: it is not one security from each market - it is ONE security overall!)

A payoff table determines the payoff. There are two different payoff tables, one for the RED type buyers, and one for the BLUE type. You can see links to them on the top of the screen when you click on the "Participate in the Sale" link. You are also given hard copies of those tables. The payoff of each buyer depends on the security bought AND on the price paid, and it is possible to have negative payoffs. 
If by the end of a period a buyer has not obtained a security he automatically receives a default payoff equal to 12 francs independently of the type. The total payoff from the experiment for a given buyer is the sum of the payoffs from all periods during the experiment.

A payoff table determines the payoff. There are two different payoff tables, one for the RED type buyers, and one for the BLUE type. You can see links to them on the top of the screen when you open the "Participate in the Sale" page. You are also given hard copies of those tables. Each buyer is given both tables. Tables have columns A, B, C, ... , O, denoting the names of the securities, and rows 1, 2, $3, \ldots, 23$, denoting the possible prices of those securities. If a buyer is RED type for a given period the RED-type-payoff table is to be used in that period. Similarly if you are a BLUE type buyer, the BLUE-type-payoff table is to be used in this period. The payoff of each buyer depends on the security bought (column) AND on the price paid (row), and it is possible to have negative payoffs. If by the end of a period a buyer has not obtained a security he automatically receives a default payoff equal to 12 francs independently of the type. The total payoff from the experiment for a given buyer is the sum of the payoffs from all periods during the experiment.

At the end of the experiment, each franc will be converted to dollars. The conversion rate is going to be announced privately to each buyer in the beginning of the experiment. You will be able to find it on the message board in the bottom of your screen. Below are parts of the tables presented to the buyers. [Tables Here]

For example, if you are a RED type of buyer and you choose to buy security $\mathrm{C}$ at price 5 , your payoff for the period is going to be 50 francs. If you are a BLUE type of buyer and you choose to buy $\mathrm{C}$ at price 5 , your payoff is going to be 45 francs. As can be seen from the tables, you can have negative payoff if you trade certain securities at certain prices depending on your type.

-Sellers: Sellers can offer securities to the buyers. Sellers are allowed to offer and sell as many securities as they want. The sellers only know that each period there are 9 RED and 8 BLUE types of buyers in the market. They do not know which of the buyers are RED and which are BLUE.

If a seller does not participate in any transaction during a given period her payoff for that period is 0 francs. However, a seller can increase or possibly decrease her payoff by participating in a transaction.

The payoff from each transaction is determined from a payoff table. The payoff depends on which security was sold, at what price, as well as on the TYPE of the buyer to whom it was sold. At the time the seller makes her offer(s), she does not know what type of buyer(s) will accept her offer(s). 
In addition to the payoff from the table, there are 15 francs commission that a seller gets from her FIRST contract sold, i.e., if you are a seller, and you sell 2 contracts with payoffs of 10 and 20 francs, 15 francs are added to the first one and thus your total payoff becomes $45(10+15+10)$ francs. Below is a part of the table presented to the sellers: [Table Here]

The columns of the table A, B, C, .., O denote the names of the securities, while the rows $1,2,3 \ldots, 23$ denote the possible prices for those securities. Each cell of the sellers' payoff table consists of four entries. The payoff from transactions with buyers of type BLUE is in bold BLUE. The payoff from transactions with buyers of type RED is in bold RED. The payoffs of the buyers are given in parenthesis below the corresponding seller's payoff (in red for the RED buyers and blue for the BLUE buyers).

Thus, if you are a seller and you offer, say, 1 unit of $\mathrm{C}$ at price 5, your payoff would depend on what type of buyer (if any) is going to buy this unit. If it is bought by a RED buyer, your payoff from the transaction is -16 francs. The buyer's payoff is 50 (given in red in parenthesis). If a BLUE type of buyer buys your unit, your payoff from the transaction is 29 francs. The blue buyer's payoff is 45 francs. You will not know the types of the buyers who participated in transactions with you until the end of the period. Only after the end of the period, the types of the buyers will be revealed and payoffs will be realized.

The total payoff (in francs) from the experiment for a given seller is the sum of the payoffs from all periods during the experiment.

At the end of the experiment your total payoff will be converted to dollars at an exchange rate that is going to be privately announced in the beginning of the experiment. You will be able to find it on the message board in the bottom of your screen.

Important!!! Anybody (buyer or seller) who has negative total earnings for more than two periods in a row will be excluded from further trading and will receive nothing at the end of the experiment.

\section{Glossary of important market elements}

OFFERS:

Buyers and sellers, open the "Participate in the Sale" web page.

SELLERS:

Each cell on the trading screen has four entries: a/b c/d (all equal to zero in the beginning of each period).

"a" is the number of units you sold at this market and price 
"b" is the number of units sold by all sellers in this market and price

"c" is number of units currently offered by you in this market and price

"d" is the total number of units currently offered by all sellers in this market at that price.

If you are a seller and you submit a SELL OFFER for a given security at a given price, this means that you are willing to sell the security to anyone at that price. If no one accepts the offer (how offers are accepted is explained later in the text) it goes unfilled. Your unfilled offer remain on the trading screen until it is cancelled by you, is taken by a buyer, or the period is over.

If you are a seller, you may place sell offers for any number of units. The computer will automatically fill orders if possible. If you want to place an order, you have to click (in order to highlight it) on the cell indicating the market and the price you want to submit order at, and then click on the "submit offer" button. Each click on the "submit offer" button adds one more unit to the ones that are already offered at the market and the price indicated by the highlighted cell.

If you want to cancel a still unfilled offer, you have to click on the cell where you placed the offer and then click on the "Cancel Offer" button. Each click cancels one of your outstanding offers.

\section{BUYERS:}

Each cell on the trading screen consists of two numbers a/b (both equal to zero in the beginning of each period). "a" is the number of units bought by all buyers in this market and price, while "b" is the number of units currently offered in this market and price.

If you are a buyer, you will only be allowed to submit orders at those markets and prices for which there are already offers from the sellers (i.e., you can click on cells with posted offers only). If you attempt to submit a buy order for which there is no counter sell order, your order will be automatically cancelled and no one will see that you placed such an order. You are allowed to accept at most one buy order per period. When you decide which of the offers to accept, you have to click on that offer to highlight it and then hit the "submit order" button. When the order is processed successfully, the market and the price cell is highlighted in red. You will not be able to cancel a once submitted order.

If there is more than one seller who offered a security at a given price, whenever a buy offer comes, one of the sellers is going to be chosen randomly and her security will be the one sold to the buyer. NOTICE: orders are not executed chronologically. A seller is chosen randomly each time there is more that one seller offering a given security at a given price. Thus, submitting many orders does not improve your chances of being chosen as long as you have at least one outstanding order. 